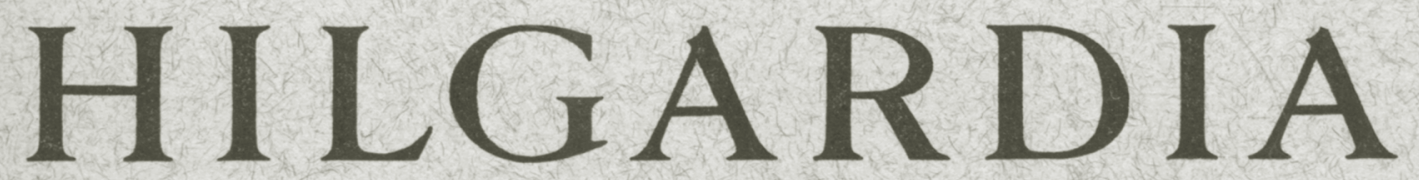

A Journal of Agricultural Science Published by the California Agricultural Experiment Station

\title{
ABSORPTION AND TRANSLOCATION OF 2,4-D AND AMITROLE \\ IN SHOOTS OF THE TOKAY GRAPE
}

\author{
O. A. LEONARD \\ and \\ R. J. WEAVER
}

UNIVERSITY OF CALIFORNIA - BERKELEY, CALIFORNIA 


\begin{abstract}
Absorption and translocation of foliar-applied 2,4-D and amitrole were studied in shoots of the Tokay grape. The major aspect of this study involved investigating the relationship of the position of the treated leaves to the fruit clusters and to the age of the clusters. The techniques of autoradiography - extraction and purification, counting, and chromatography - were used. Such studies were conducted at various periods following application, the maximum time lapse being 112 days.

Physiological significance of the findings is discussed, and practical aspects are considered.
\end{abstract}




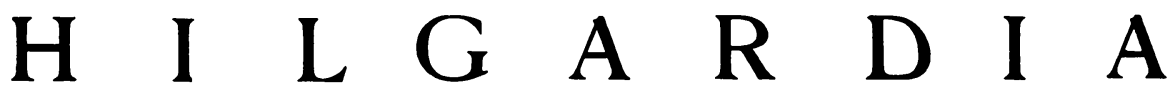

A Journal of Agricultural Science Published by

the California Agricultural Experiment Station

VoL. 31

NOVEMBER, 1961

No. 9

\section{ABSORPTION AND TRANSLOCATION OF 2,4-D AND AMITROLE IN SHOOTS OF THE TOKAY GRAPE ${ }^{1}$}

\section{O. A. LEONARD ${ }^{2}$ and R. J. WEAVER}

\section{INTRODUCTION}

The ToKay GRAPE, grown mainly within a 5 -mile radius of Lodi, California, is very sensitive to 2,4-D (2,4-dichlorophenoxyacetic acid), which frequently drifts over the vineyards from grain fields to the west. Such spray drift has long been a factor limiting the use of 2,4-D in and near vineyards, and recently the problem of residue has also become an important consideration. Amitrole (3-amino-1,2,4-triazole) is also an important herbicide. It would be a useful compound along with diuron or simazine in soil applications to control weeds in vineyards during the winter. Present evidence suggests that amitrole would not be likely to occur as residue in fruits following winter soil treatment (Leonard and Lider, 1961). ${ }^{4}$ Absorption of amitrole appears to be correlated with transpiration, and would therefore probably not occur during the dormant season. Furthermore, amitrole does not normally persist for long periods in the soil (Sanders, 1958).

The importance of these spray and drift problems prompted the present investigation of the absorption, translocation, and disappearance of 2,4-D and amitrole from shoots of the Tokay grape. Both 2,4-D and amitrole were used in order to compare the translocation characteristics of a normally quite mobile compound (amitrole) with 2,4-D, which is intermediate to poor in mobility. Amitrole is recognized as appreciably superior to 2,4-D with respect to translocation capacity (Crafts and Yamaguchi, 1958; Crafts, 1959). However, some evidence obtained by Leonard and Lider (1961) indicated that amitrole might have a limited movement within the grape.

Studies with labeled molecules have shown that pesticides applied to leaves may diffuse across the cuticle, migrate through living chlorenchyma into the veins, and translocate, in the phloem, with the assimilates manufactured in the leaves. Similar pesticides applied to the roots may be absorbed and translocated to the shoots via the transpiration stream. Some pesticides,

\footnotetext{
${ }^{1}$ Submitted for publication May 10, 1961.

${ }^{2}$ Lecturer in Botany, and Botanist in the Experiment Station, Davis.

${ }^{3}$ Professor of Viticulture, and Viticulturist in the Experiment Station, Davis.

"See "Literature Cited" for citations referred to in the text by author and date.
} 
notably the substituted ureas and the symmetrical triazines, are apparently unable to enter and move in the phloem; however, they may be readily absorbed by roots and transported to leaves. Some compounds, furthermore, may move readily in either phloem or xylem. Still other compounds move largely in the phloem, but may be induced to move in the xylem as a result of injury.

Several studies have been made concerning the sensitivity of the grape (Vitis vinifera) to 2,4-D and amitrole. Weaver, Winkler, and McCune (1958) presented some data on the effect of 2,4-D on the grapevine. Weaver, Leonard, and McCune (1961) studied the sensitivity of grape clusters, at different stages of development, to 2,4-D, 2,4,5-T and 4-CPA. They found that toxicity to the clusters was least with 4-CPA, next with 2,4-D, and greatest with 2,4,5-T, and that 2,4-D appears to remain unaltered for a relatively long period of time in the clusters. Clore and Bruns (1953) reported that the Concord grape produced foliage symptoms with as little as $0.0001 \mu \mathrm{g}$ of 2,4-D. This figure seems to be too low, since Weaver, Winkler, and McCune (1958) observed that $0.1 \mu \mathrm{g}$ of 2,4-D applied to a growing bud was required to produce a detectable symptom in both Concord and Tokay varieties. Furthermore, in the present work, the symptoms produced with even 20- $\mu$ g applications to mature leaves were never more than minor, and failed to develop at all when the very young leaves were treated. However, very little 2,4-D migrated out of the young leaves because the treatment was injurious to them.

Amitrole frequently appears to be readily absorbed by the leaves of plants (Leonard and Yeates, 1959 ; Crafts and Yamaguchi, 1958), including grape, as found in the present study. Difficulty in obtaining absorption of 2,4-D was encountered by Leonard and Crafts (1956), and Clor (1959) with some species of woody plants, including interior live oak (Quercus wislizenii) and blue oak (Q. douglasii). A similar difficulty was encountered by Leonard and Yeates (1959) in the absorption of 2,4-D and 2,4,5-T by the leaves of gorse (Ulex europeus) and Scotch broom (Cytisus scoparius). Currier and Dybing (1959) have reviewed some of the problems relating to the penetration and absorption of herbicides by leaves.

The absorption of amitrole is favored by a high relative humidity (Leonard and Yeates, 1959). Clor (1959) showed that a saturated atmosphere greatly improved the absorption of 2,4-D by interior live oak, blue oak, and cotton (Gossypium hirsutum). A similar observation was made with 2,4,5-T on gorse and broom leaves by Leonard (1961) and on white fir (Abies concolor) by Leonard and Hull (unpublished). An atmosphere slightly below saturation resulted in no improvement in the absorption of 2,4,5-T by gorse and broom leaves over that obtained with a humidity of 70 per cent (Leonard and Yeates, 1959).

Seasonal changes of carbohydrates in the grapevine were worked out by Winkler and Williams (1945). After spring growth began, the percentage of readily available carbohydrates decreased throughout the plant, while a earbohydrate build-up occurred in the roots during August-September. This is in agreement with observations made in the present study on movement of 2,4-D and amitrole.

A. J. Winkler (1932) has shown that available carbohydrates produced in one portion of a vine readily translocated to clusters located in other parts 
of the vines. In contrast, 2,4-D is more restricted in its movement than are the soluble carbohydrates. For example, it is possible to kill one cordon of a vine with 2,4-D without injury to the other (Weaver, unpublished data).

The grape ranges from moderately tolerant to resistant to amitrole (Lider, Leonard, and Sisson, 1961). Zinfandel is moderately tolerant, and the St. George Rupestris rootstock is resistant. The latter variety showed no visible effect one year after application of a wetting spray with 8 pounds of amitrole per 100 gallons of water. In the present work, no symptoms of any kind were produced with $60-\mu \mathrm{g}$ applications of labeled amitrole applied to either mature or immature leaves.
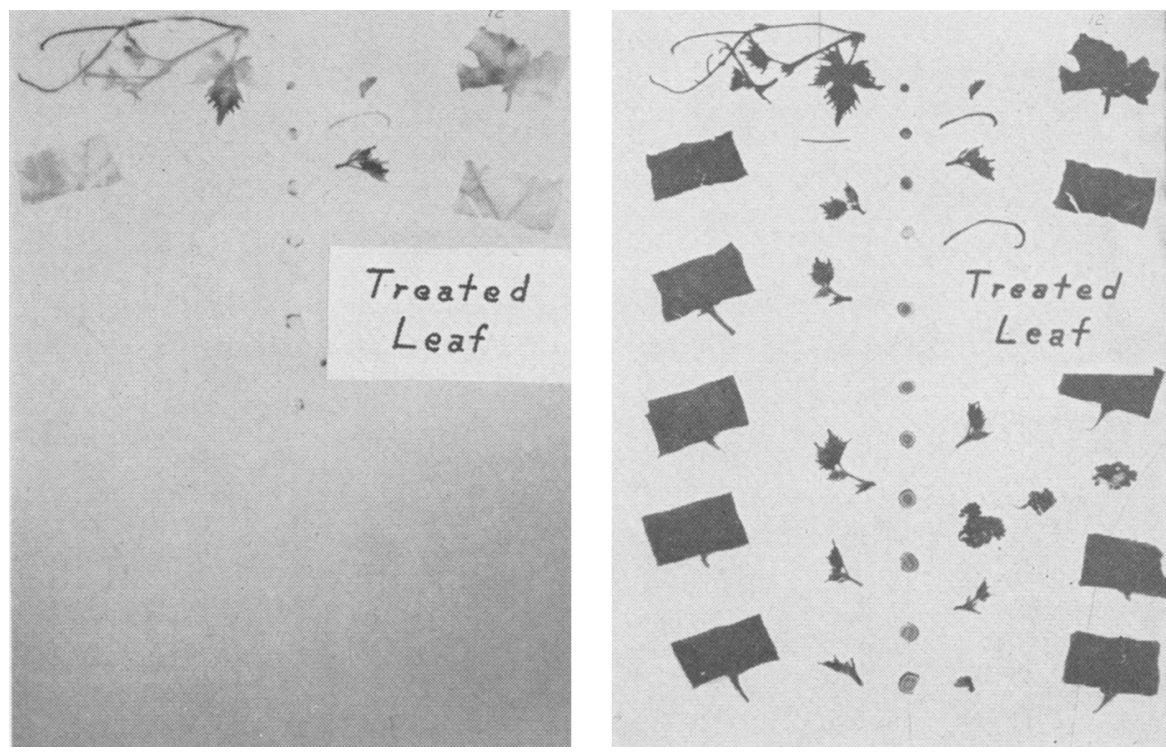

Fig. 1. Second leaf above cluster was treated with amitrole on May 9, 1960, three clays before collection. Autoradiographs, left; mounted specimens, right.

\section{MATERIALS AND METHODS}

Mature vines of Tokay grapes used in these studies were in an irrigated vineyard at Davis. The vines were cordon-trained and spur-pruned. Both compounds used were carbon-14 labeled. The 2,4-D was carboxyl labeled, and the amitrole as indicated in the formula: 3-amino-1,2,4-triazole-5- $\mathrm{C}^{14}$. The specific activity of the 2,4-D in experiment 1 was $1.24 \mathrm{mc} / \mathrm{mM}$, and in experiments 2,3 , and $4,12.3 \mathrm{mc} / \mathrm{mM}$. The specific activity of the amitrole was $2.3 \mathrm{mc} / \mathrm{mM}$ in all experiments. The compounds were dissolved in 50 per cent ethanol containing 0.1 per cent Tween 20 (polyethylene sorbitan monolaurate), known to increase markedly the absorption of 2,4-D (Leonard, 1958). All of the 2,4-D applications were $20 \mu \mathrm{g}$ per treatment, and of the amitrole, $60 \mu \mathrm{g}$ per treatment. Applications of 5 or 20 microliters were made to the basal portion of the upper surface of the leaf blades, by means of a microsyringe. An attempt was made to treat the midrib and the large veins to facilitate entry of the compounds into the conducting tissues. 


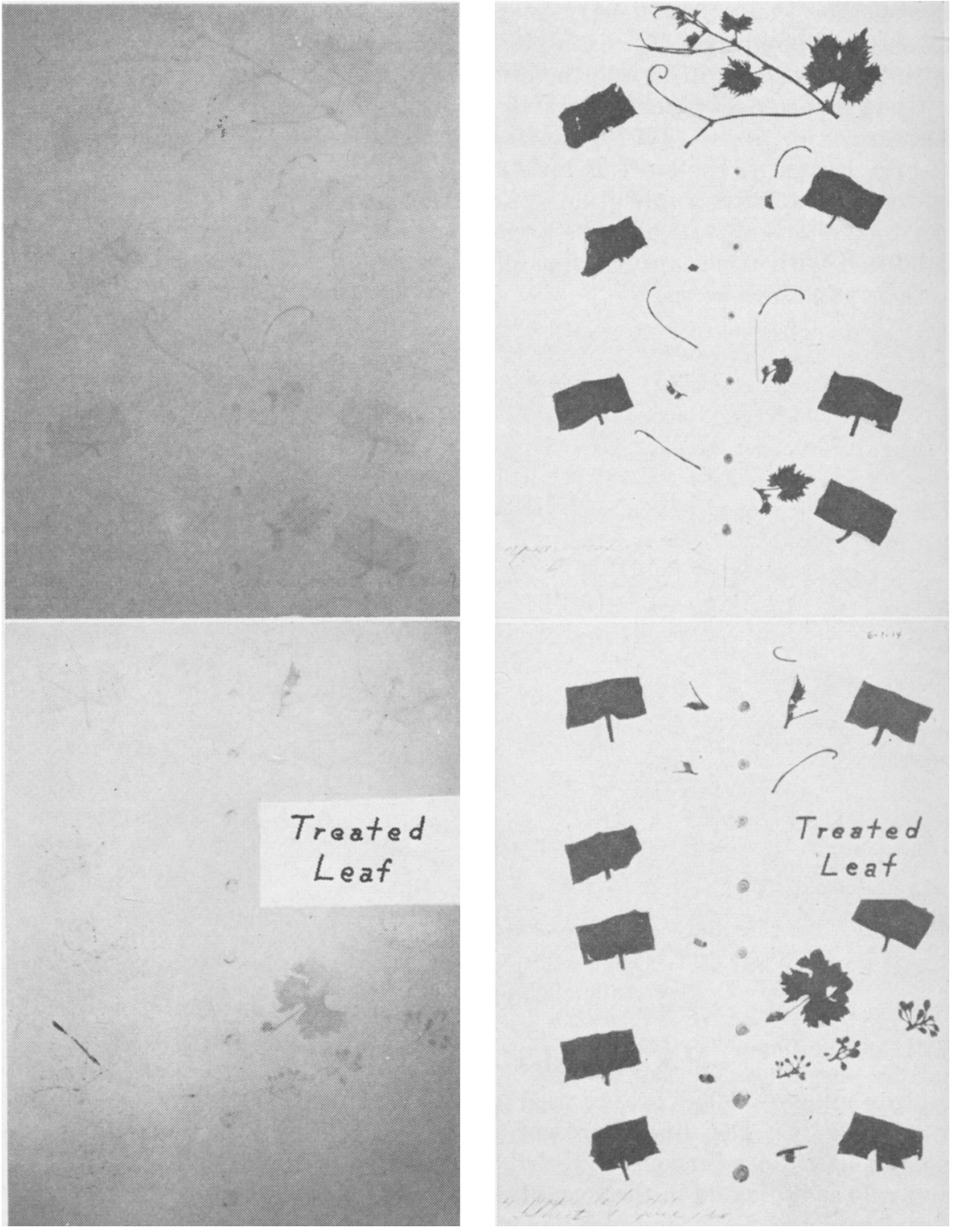

Fig. 2. Second leaf above cluster was treated with amitrole on May 9, 1960, 23 days before collection. Autoradiographs, left ; mounted specimens, right. 

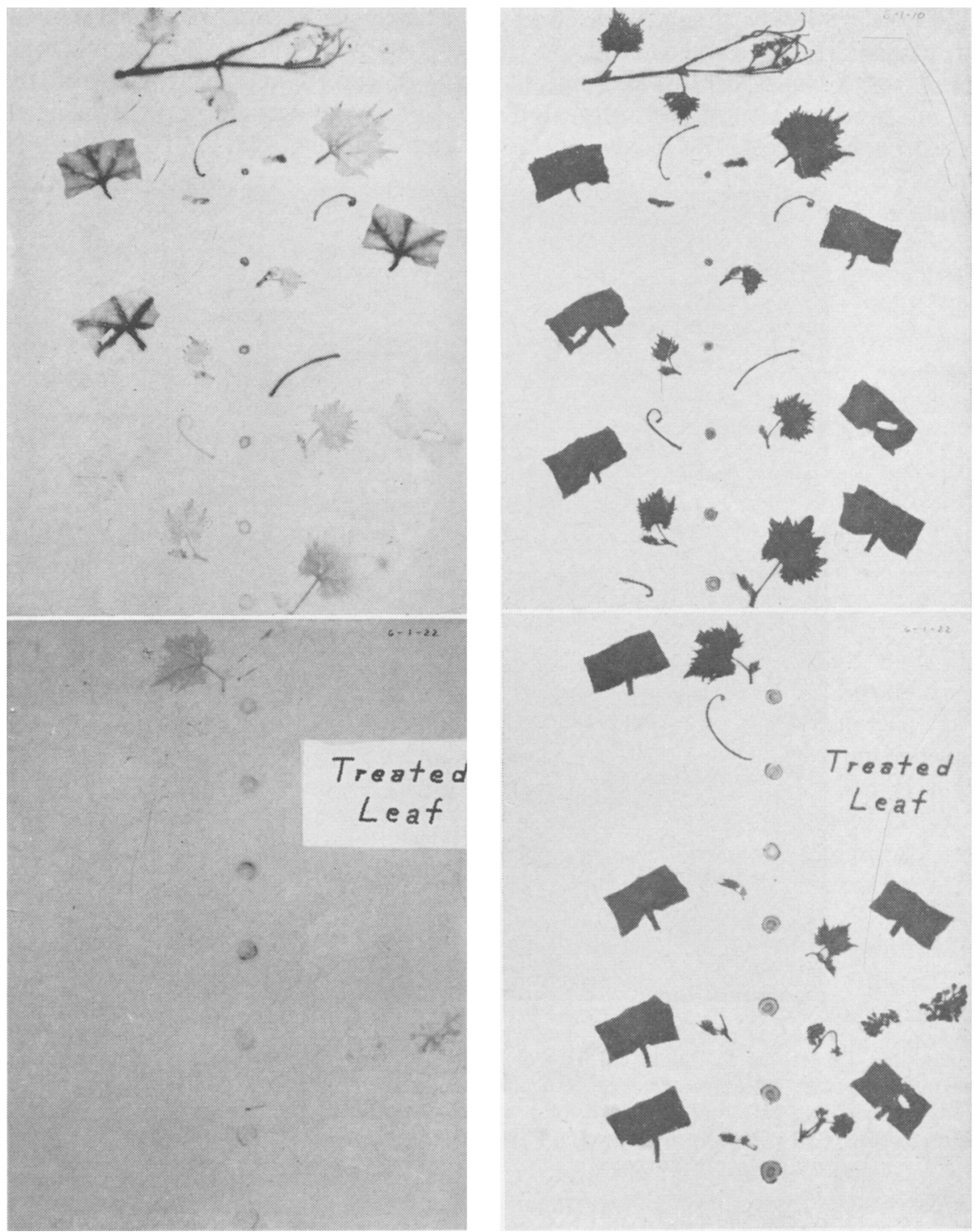

Fig. 3. Second leaf above cluster was treated with 2,4-D on May 9, 1960, 23 days before collection. Autoradiographs, left; mounted specimens, right. Three-day treatment is not presented because autoradiographs were not strong enough to reproduce. 
Three replicate shoots were used per treatment except in experiment 4, in which two shoots were used. At time of treatment the maximum width of the treated leaves, length and weight of the flower clusters, and length of the shoots were measured. An untreated series of shoots was similarly measured.

At each harvest, the leaves were cut from the shoots, dried in an oven at

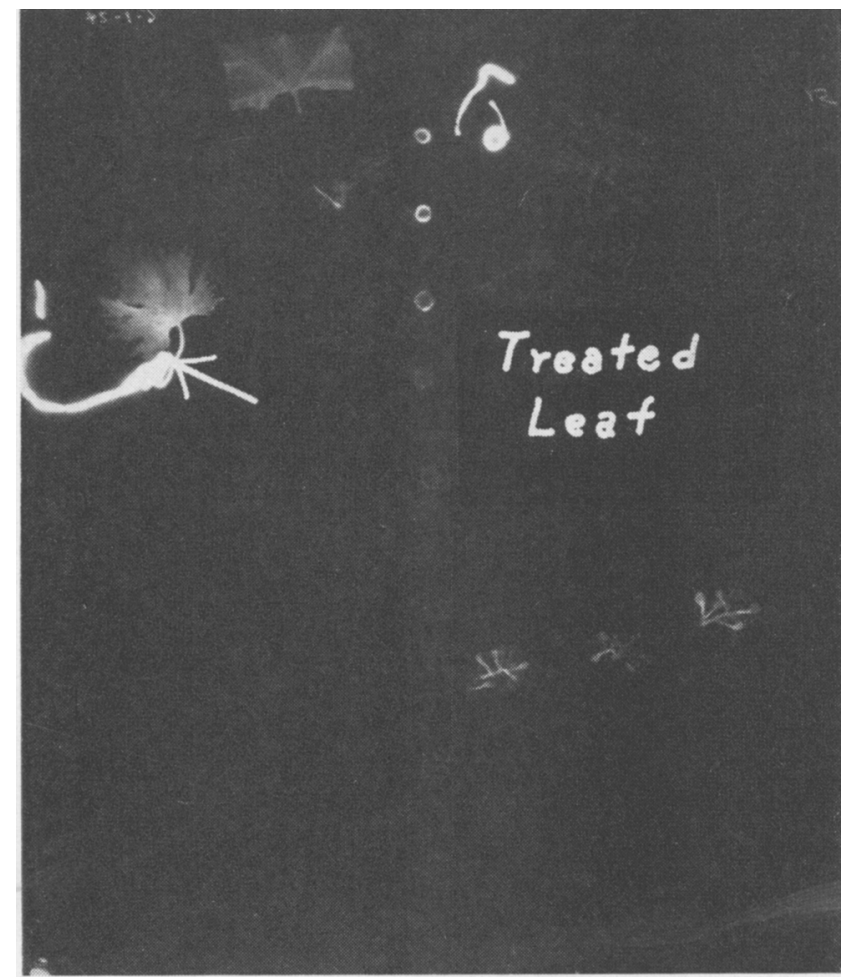

Fig. 4. Second leaf above cluster was treated with 2,4-D on May 9, 1960, 23 days before collection. Treatment was identical with one shown in figure 3, except that shoot was inadvertently broken off after treatment. Arrow points to broken apex to left of autoradiograph. Tendrils (left and top) are very radioactive. Note labeling in three portions of clusters located beneath treated leaf. (This autograph and those in figures 17 and 20 are positives; all others are negatives.)

$45^{\circ} \mathrm{C}$, and weighed. The dried leaves were then ground in a small mill. Some of the powder, to be used for determining the radioactivity of the treated leaves, was placed in planchets.

The shoots were removed from the vines with pruning shears, placed in polyethylene bags to reduce evaporation, and taken at once to a cold room samples were prepared from part of the basal portion of each leaf and the at $5^{\circ} \mathrm{C}$. On the same day, the shoots were removed from the cold room, and bud in the axil of each leaf (figs. 1 to 4 ). If the bud had developed into a shoot, only the apical 1 - or 2 -inch portion was used. One stem cross-section was taken from near the middle of each internode with a razor blade. Tendrils or portions of tendrils were also used. The flower or fruit clusters were 
sampled by taking branches from the basal, middle, and apical portions. (It should be mentioned here that grape shoots have a bilateral phyllotaxy; in other words, leaves and buds arise alternately on opposite sides of the stem.) Leaves above the clusters were apical to, and on the same anatomical side of the stem as the cluster.

All parts were arranged in their natural phyllotactic order, on $10 \times 12$-inch sheets of white paper, and held in place with a casein-type glue. The sheets were clamped between wire netting and paper towels, and the specimens were dried at $45^{\circ} \mathrm{C}$. When dried, the specimens were humidified, placed in a herbarium-like press, and dried again (Yamaguchi and Crafts, 1958). The sheets were placed on Kodak No-Screen X-ray film for 30 days, after which the film was developed. The untreated check specimens usually produced from very dim to appreciably clear autographs. The autographs from the untreated plants were produced by chemicals in the plant tissues that precipitated the silver in the film, and may be termed chemical autographs. The intensity of these autographs increased with age of the shoots. In addition, there was a small amount of inorganic beta radiation (since ashing the tissues did not alter the counts appreciably) which may have been largely potassium 40 (Leonard and Lider, unpublished). It was possible to eliminate the chemical autographs by covering the mounted specimens with Saranwrap, but the intensity was also reduced by approximately 60 per cent. The autographs shown in figures 1 to 4 were made without Saranwrap to avoid increased difficulty of reproduction. The very slight autograph that persisted after the use of Saranwrap was likely the result of the low level of beta radiation from the inorganic sources. It was necessary to compare the intensity of the autographs from treated and untreated plants in deciding whether the autographs were the result of the treatments. In general, however, this was not considered a serious problem with respect to interpretation of the results.

A sample of flower and fruit clusters (except for the portion mounted on paper for autographing) was weighed and placed in a bottle containing 95 per cent ethanol. The sample was later ground in a blender and filtered twice. The residue was dried, and about $0.2 \mathrm{gm}$ was placed in a planchet and pressed down with a flat steel rod. Two $\mathrm{ml}$ of the filtrate were placed in a planchet and dried in an oven at $45^{\circ} \mathrm{C}$. The samples were weighed, the radioactivity was determined, and the counts were corrected for self absorption. The great dilution of the $\mathrm{C}^{14}$-labeled compounds in the fruit from the ripe grapes made determination of the radioactivity difficult, since the readings were close to background; however, it was not difficult to determine the amount of 2,4-D and amitrole in these samples after they had been purified. The purification procedure used for 2,4-D was the one described by Leonard, Weaver, and Kay (in press). The total activity of the ethyl ether extracts and their purity were determined by one-way descending paper chromatograms, using 79 per cent isopropanol, 20 per cent ammonium acetate (a 20 per cent aqueous solution), and 1 per cent glacial acetic acid. The chromatograms were placed on X-ray film for 30 days, and the location of the radioactive spots was noted. Radioactive 2,4-D appeared to be the only labeled compound in the ether extracts except in those from the collections made when the fruit was ripe. 


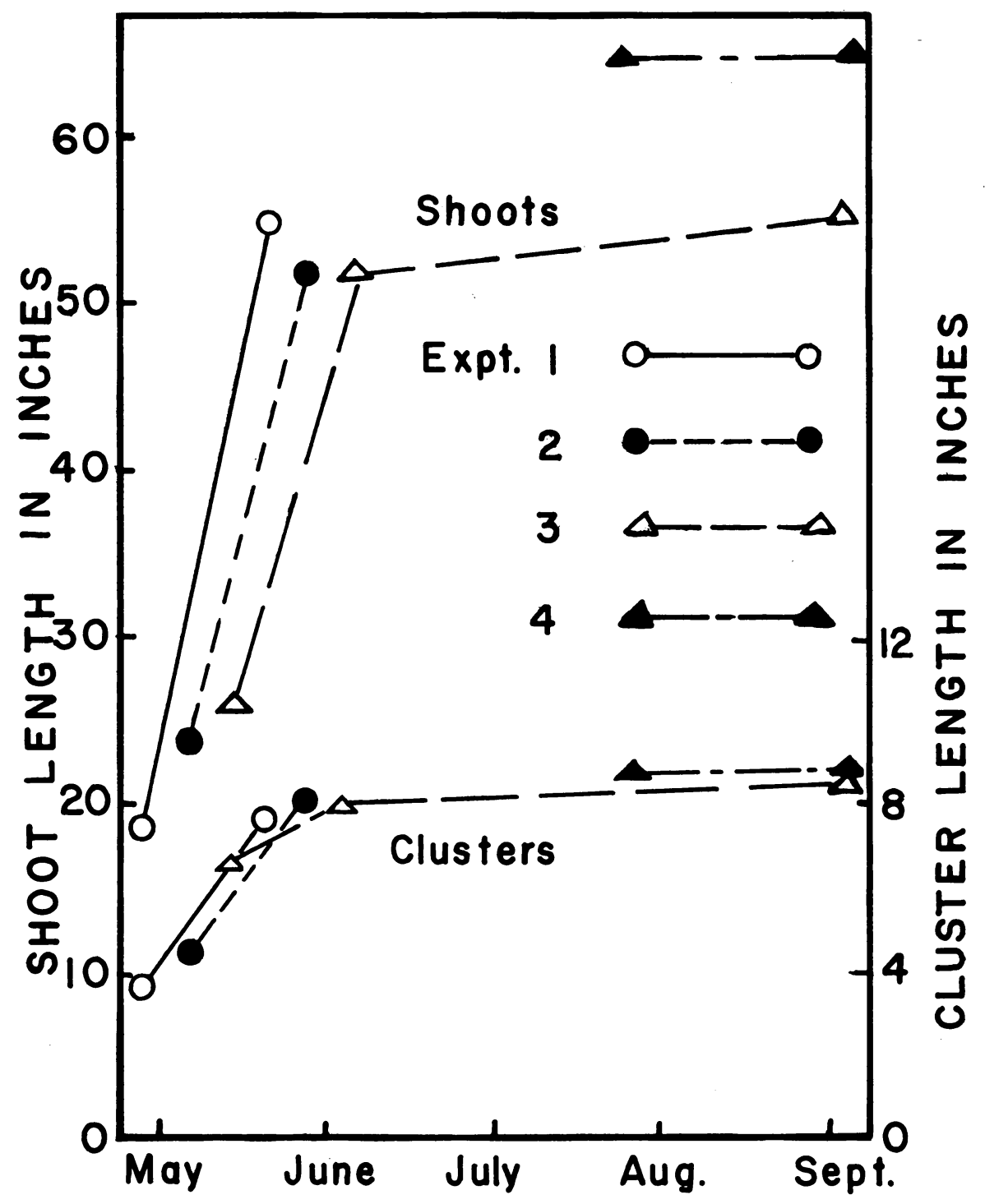

Fig. 5. Length of shoots and clusters of untreated Tokay grapes in experiments $1,2,3$, and 4 .

Amitrole was determined by evaporating the ethanol on a water bath and taking up the syrup in 80 per cent methanol. The amitrole was removed from the methanol on a cation-exchange resin column according to the method described by W. O. Winkler (1959). The amitrole was eluted from the exchange column with $\underline{\mathrm{N}} \mathrm{NH}_{4} \mathrm{OH}$, and the activity in the eluate was determined. Since labeled amitrole added to the extracts of untreated fruit could be completely recovered by this procedure, it was regarded as quite 
reliable. Amitrole was chromatographed by means of a solvent system consisting of 61 per cent butanol, 23 per cent acetic acid, and 16 per cent water, by volume.

\section{EXPERIMENTATION AND RESULTS}

Four experiments were conducted, two in 1959 and two in 1960. The stages of growth of shoots in the first three experiments were fairly similar, but there were slight differences in the lengths of the shoots and flower clusters. Such variations are normally encountered among different shoots, and in different years. Differences in the patterns of translocation obtained in these

TABLE 1

STAGE OF DEVELOPMENT OF TREATED LEAVES, SHOOTS, AND CLUSTERS OF TOKAY GRAPES FOLLOWING TREATMENT WITH 2,4-D AND AMITROLE

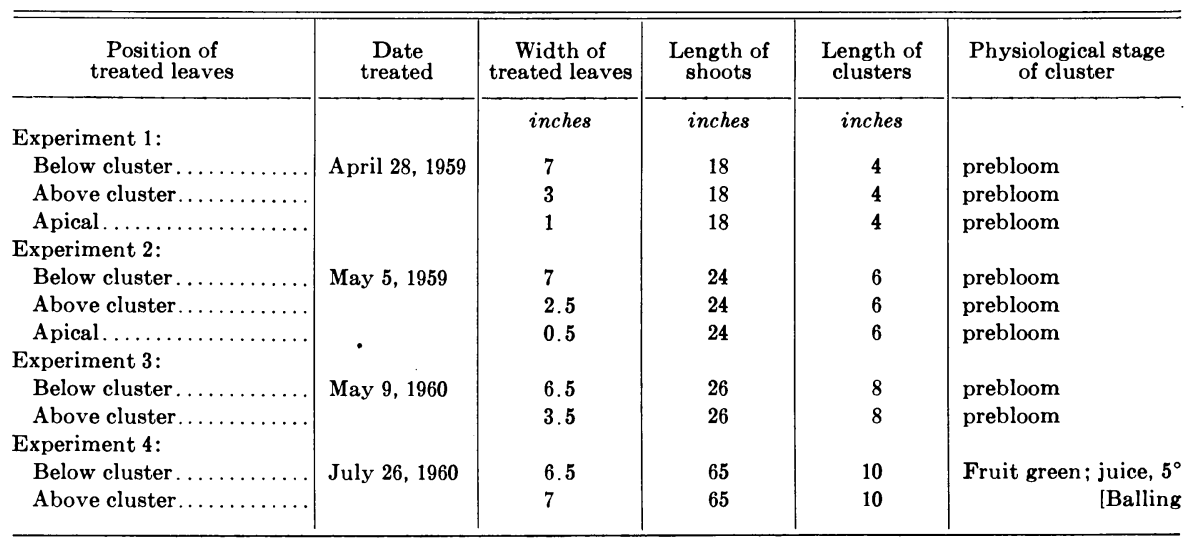

experiments are interpreted as being either due to or associated with these small differences in shoot growth and in stage of development of the flower cluster (fig. 5). There were greater differences in development between clusters than between shoots. The fourth experiment was conducted at a much later date than the first three, and the stage of development of shoots and of flower clusters (by this time fruit clusters) was entirely different.

In the first three experiments (table 1), the leaf immediately beneath the cluster was full sized or mature at the time of treatment. The leaf above the cluster (the first leaf above the cluster in experiment 1, and the second in experiments 2 and 3 ) varied from a width of one-third to threefifths that of mature leaves when treated. The size of these leaves as related to their size at maturity had a great effect on whether they imported or exported assimilates (and hence 2,4-D or amitrole) at the time of treatment. The very small upper leaves treated in experiments 1 and 2 were importing assimilates at the time of treatment. The treatments with 2,4-D were so injurious to these small leaves that they were not treated in experiments 3 and 4.

Leaves in the same relative position on the shoots were treated in experiments 3 and 4 . They were about two and one-half months older in the latter 
experiment, and had been fully enlarged (mature) for more than two months. The treated leaves below and above the clusters were similar in appearance and probably similar physiologically.

The shoots were rapidly elongating and the cambium was quite active when the treatments were made in experiments 1,2 , and 3 ; in addition to the active vegetative growth, the clusters were growing rapidly. The situation in experiment 4 contrasted with the first three tests in that vegetative growth had greatly decreased and the berries were more than one-half their mature size. The fruit was of greater importance than was vegetative growth as a "sink" for carbohydrates in this experiment, since the total soluble solids increased from 5 to 15 per cent during the course of the experiment ( 38 days).

The translocation pattern considered typical is shown in the various figures; variations from the patterns illustrated are described.

\section{A Note on the Charts}

The following explanation applies to figures 6 to 16 and to figure 18 . The petiole is shown as a short line at each node. Leaves having radioactivity are shown as circles proportional in size to the leaves they represent. The method for showing intensity of the radioactivity is indicated in figure 6. Buds are shown as small circles next to the stem and above the petiole. Leaves and buds having no radioactivity are omitted. The nonradioactive flower or fruit cluster is shown as a straight line; when radioactive, small circles appear on the line. Radioactive tendrils are shown as forked lines. (These were always radioactive when the adjacent stem to which they were attached was radioactive.) Nonradioactive tendrils were omitted. Radioactivity in the stem is shown as hatched, cross-hatched, and solid areas (fig. 6). Nonradioactive parts of stems are blank.

Some nodes were omitted because of space limitation. Only a few of the small apical leaves and buds are shown on the charts.

\section{Experiment 1}

The shoots chosen for study varied in length from 15 to 23 inches, but averaged about 18 inches at the time of treatment (table 2). The flower

TABLE 2

EFFECT OF 2,4-D ON LEAF WIDTH AND ON SHOOT AND

CLUSTER LENGTH OF TOKAY GRAPES

(Experiment 1, April 28, 1959)

\begin{tabular}{|c|c|c|c|c|c|c|}
\hline \multirow{2}{*}{ Leaf treated } & \multirow{2}{*}{$\begin{array}{l}\text { Number of } \\
\text { days after } \\
\text { treatment }\end{array}$} & \multicolumn{3}{|c|}{ Width of: } & \multirow{2}{*}{$\begin{array}{l}\text { Cluster } \\
\text { length }\end{array}$} & \multirow{2}{*}{$\begin{array}{l}\text { Shoot } \\
\text { length }\end{array}$} \\
\hline & & Basal leaf & Middle leaf & Upper leaf & & \\
\hline & & inches & inches & inches & inches & inches \\
\hline None.... & 0 & 7.0 & 3 & 1 & 4.0 & 18 \\
\hline None..... & 21 & 6.5 & 7 & 7 & 8.5 & 55 \\
\hline Basal.............. & 21 & 6.5 & 7 & 6 & 7.5 & 45 \\
\hline Middle $\ldots \ldots \ldots \ldots$ & 21 & 7.0 & $4^{*}$ & 7 & 8.5 & 58 \\
\hline Upper........ & 21 & 7.0 & 7 & $1^{*}$ & 8.0 & 56 \\
\hline
\end{tabular}

* Leaf folded as result of treatment with 2,4-D. 
BUDS, LEAVES, CLUSTER

O --- TRACE

O --- LOW

$\Theta$---MEDIUM

---HIGH

STEM

-.- TRACE

---MEDIUM

--- HIGH

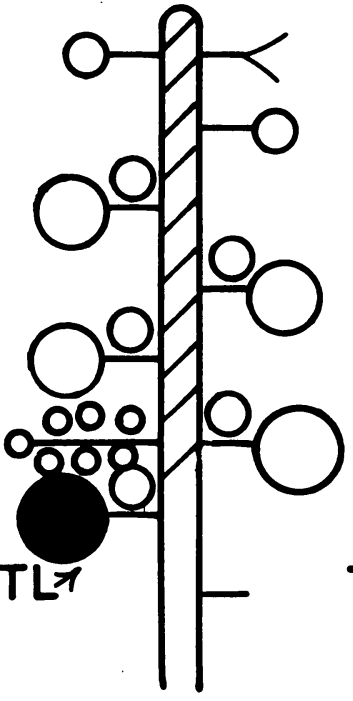

I DAY
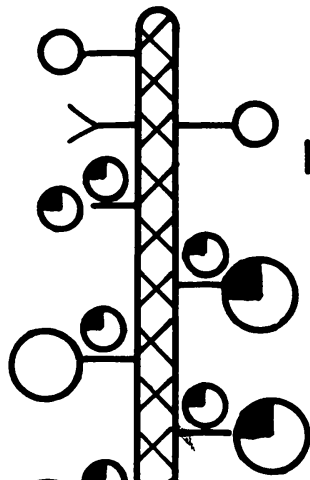

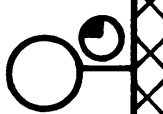
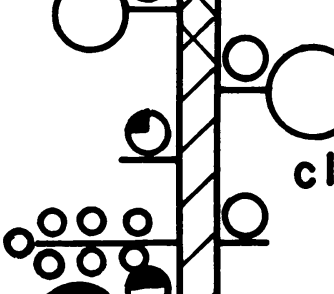

clu
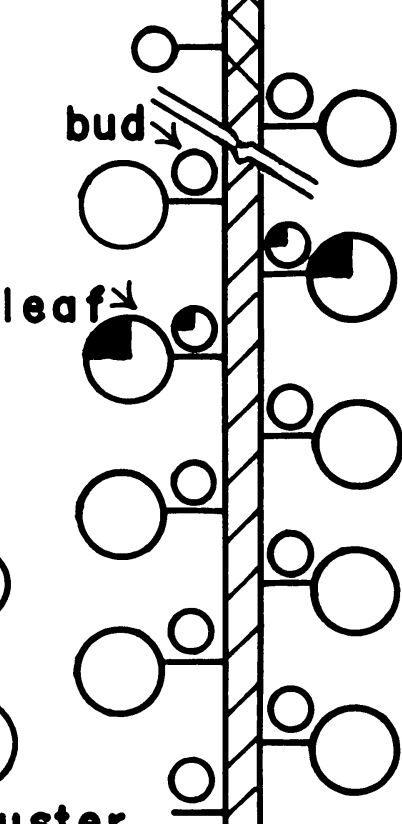

$T L$

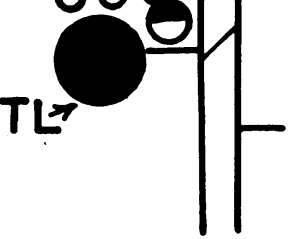

3 DAYS

\section{2,4-D LOWER LEAF TREATED}

Fig. 6. Distribution of radioactivity in the Tokay grape shoot one, three, and 21 days after treatment with labeled 2,4-D, on April 28, 1959. Treated leaf (TL) was first leaf directly beneath cluster. Nonradioactive buds, leaves, and tendrils are omitted. (See "A note on the charts," p. 336.) 


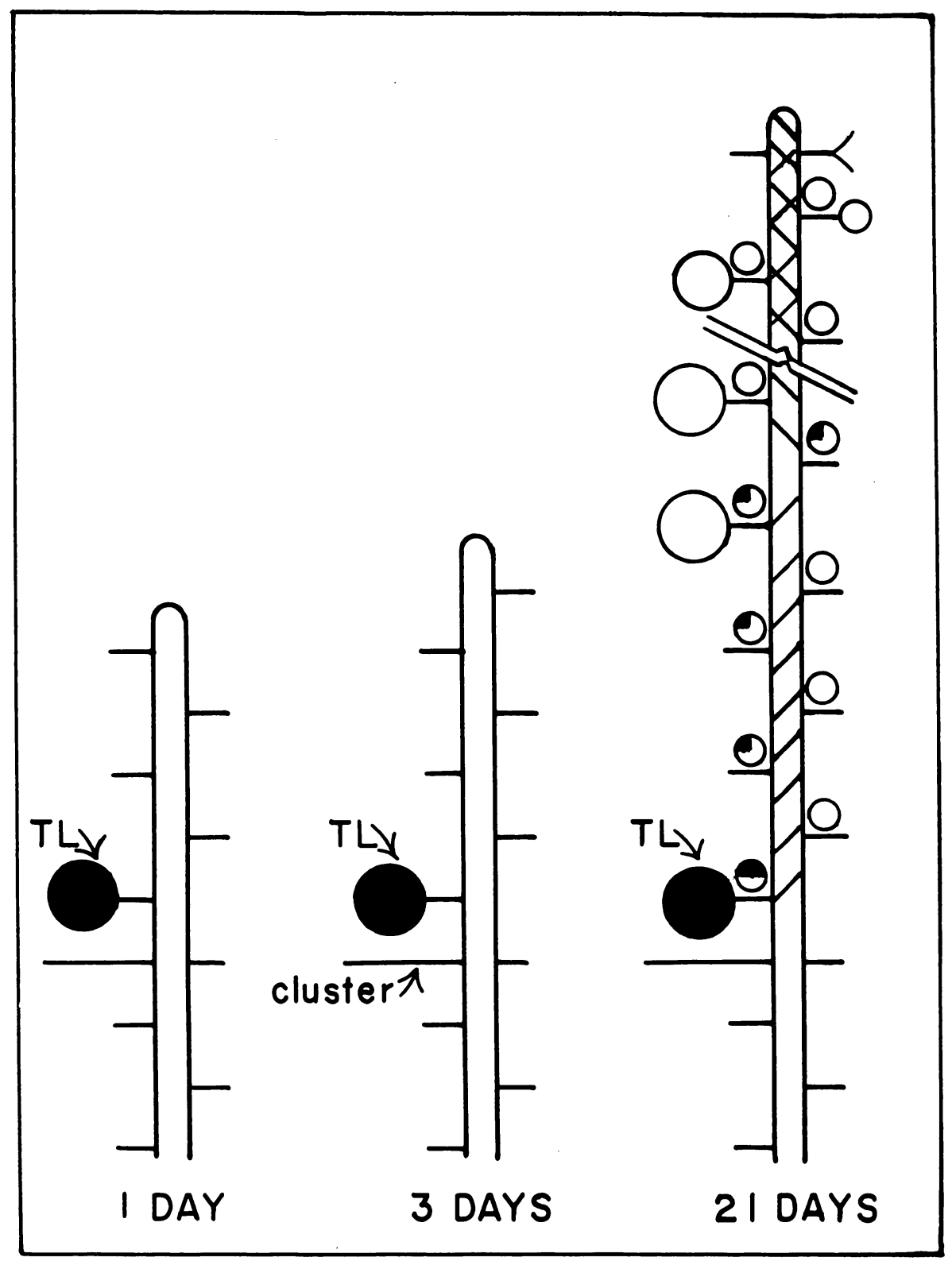

\section{2,4-D MIDDLE LEAF TREATED}

Fig. 7. Distribution of radioactivity in the Tokay grape shoot one, three, and 21 days after treatment with labeled 2,4-D on April 28, 1959. Treated leaf (TL) (3.5 inches wide) was first leaf directly above center. (See "A note on the charts," p. 336.) 
clusters were about 4 inches long. Treatment was made on April 28, 1959.

Translocation of 2,4-D from the lower treated leaves was immediate, but entirely upward (fig. 6). All of the leaves, buds, flower clusters, tendrils, and stem sections above the treated leaf had radioactivity within 24 hours following treatment. The lower treated leaf had just become full sized by time of treatment while the leaves directly above the clusters were about one-half the width and one-fifth the weight of mature leaves. The autoradiographs were appreciably darker three days after treatment than they were one day after treatment. Most radioactivity was present 21 days after treatment. This indicates a continued export of 2,4-D from the lower treated leaf. The leaves directly opposite the cluster and the first leaf above the cluster lost their radioactivity, indicating that this activity was exported from those leaves. It is likely that they became exporting leaves within a short period after they had imported a small amount of 2,4-D. The cambial and phloem areas of the stems showed appreciable accumulation of activity. The greatest accumulation, as noted 21 days after treatment, was in the flower clusters, but the apical portions of the stems and the tendrils also showed considerable activity.

The leaf blade of the lower treated leaf folded only very slightly as a result of treatment with $20 \mu \mathrm{g}$ of labeled 2,4-D, but the petiole did bend downward at a marked angle (to 90 degrees). The shoots appeared to be otherwise unaffected one and three days after treatment, but some malformed leaves had developed by 21 days. The malformed leaves were less than $1 / 2$ inch wide at time of treatment. Neither new leaves on lateral shoots that developed below the treated leaf nor those that developed from the leaf bud opposite the cluster showed formative effects. However, all remaining leaves developing from axillary buds apical to the treated leaf were slightly malformed and all were radioactive. Shoot elongation was probably slightly retarded as a result of treatment (table 2).

The leaf above the cluster was importing at the time of treatment, as shown in figure 6 . When these leaves were treated (fig. 7), they did not export until more than three days after treatment. However, they eventually did export, and translocated considerable activity into the shoots apical to them. The flower cluster was not a sufficiently strong sink to induce a reversal in the movement of the 2,4-D even though the actual distance from the source was only 3 to 4 inches. It may be noted that five of the leaves apical to the treated leaf had no activity, indicating that they had become exporting leaves, perhaps ahead of the treated leaf. It will be noted in table 2 that treatment of the immature leaves (middle and apical) did markedly influence their subsequent development; this retardation in growth delayed the time that they became exporting. It is likely that some of these five leaves imported a trace of 2,4-D from the treated leaf and that this was immediately exported. The leaves above these five showed appreciable radioactivity.

The buds in the axil of the treated leaf and those apical to it were all radioactive 21 days after treatment. The greatest concentration was in the bud axillary to the treated leaf and in those directly above it.

The leaf blades of the middle treated leaves were markedly folded one and three days after treatment, and somewhat moderately so 21 days after treatment. No symptoms developed on any of the leaves that were present 


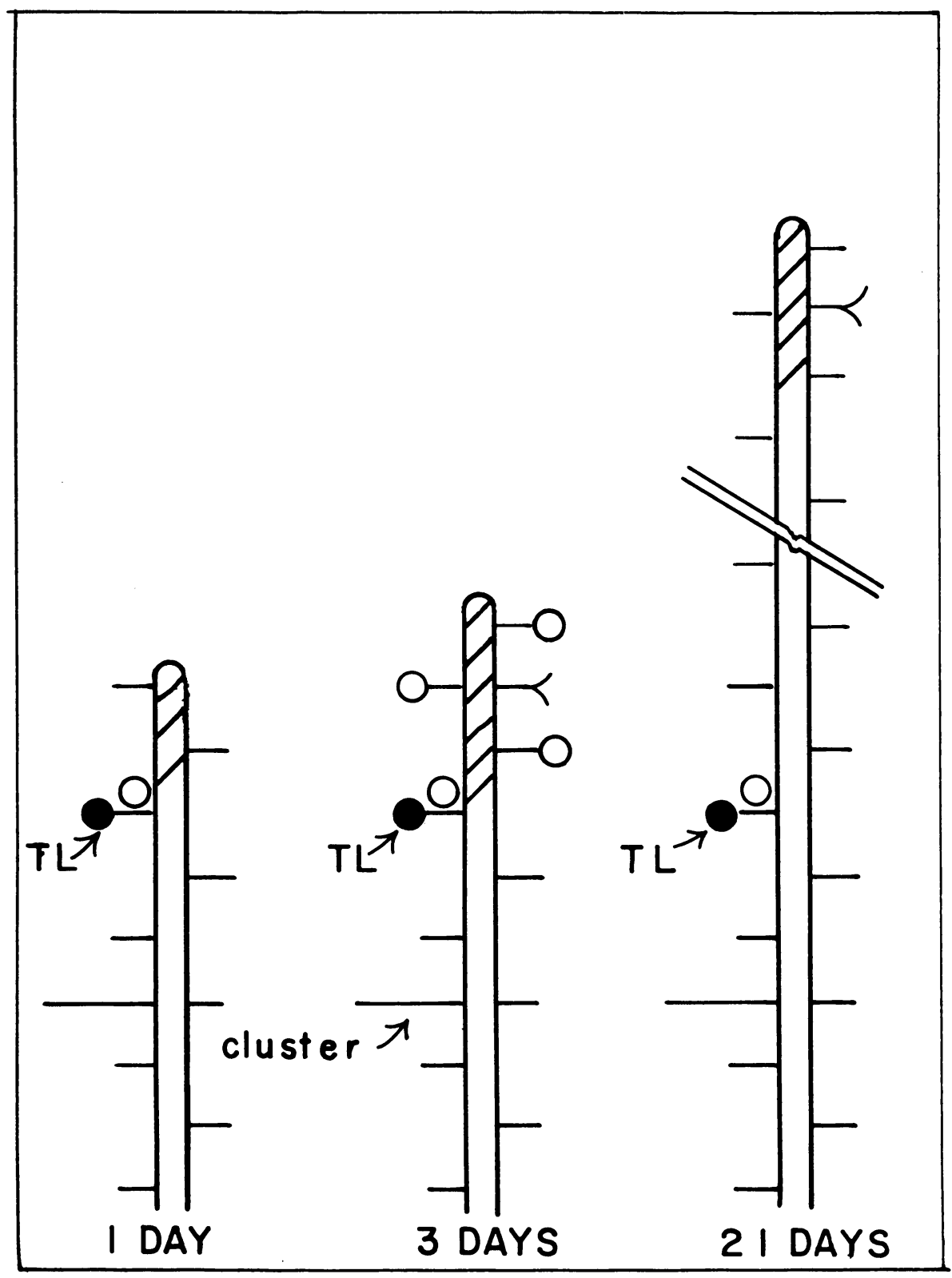

\section{2,4-D UPPER LEAF TREATED}

Fig. 8. Distribution of radioactivity in the Tokay grape shoot one, three, and 21 days after treatment with 2,4-D on May 5, 1959. Treated leaf (TL) (2.5 inches wide) was the second leaf directly above cluster. (See "A note on the charts," p. 336.) 
at the time of treatment. Slighly malformed leaves occurred on newly developing shoots from the axillary bud of the treated leaf and, in a few instances, on lateral shoots arising from nodes apical to it. The treated leaves more than doubled in weight during the 21 days following treatment, but the increase in width was slight.

The translocation pattern from the small upper leaves (fig. 8) was somewhat different from those of the immature middle treated leaf (fig. 7) and the mature lower leaf (fig. 6). The treatment was injurious to these small upper leaves, a portion of the blade contacted by the 2,4-D being blackened or killed within one day after treatment. A small amount of activity did migrate out of the treated leaf, even one day after treatment, and some activity was evident in the apical portions of the shoot three and 21 days following treatment. A small amount of activity was present in the leaves above the treated leaf three days after treatment, but was gone or nearly gone 21 days after treatment. The bulk of the activity appeared to be in the stem apex and tendrils.

The only visible effect of the treatment on the shoots was in the treated leaves (table 2), which were partially blackened and failed to grow following treatment with $20 \mu \mathrm{g}$ of labeled 2,4-D.

\section{Experiment 2}

This experiment was begun on May 5,1959 . The shoots chosen for study varied in length from 22 to 25 inches, averaging about 24 inches at time of treatment (table 3 ). The flower clusters still at a prebloom stage averaged

TABLE 3

EFFECT OF 2,4-D ON LEAF WIDTH AND ON SHOOT AND CLUSTER LENGTH OF TOKAY GRAPES

(Experiment 2, May 5, 1959)

\begin{tabular}{|c|c|c|c|c|c|c|}
\hline \multirow{2}{*}{ Leaf treated } & \multirow{2}{*}{$\begin{array}{l}\text { Number of } \\
\text { days after } \\
\text { treatment }\end{array}$} & \multicolumn{3}{|c|}{ Width of : } & \multirow{2}{*}{$\begin{array}{l}\text { Cluster } \\
\text { length }\end{array}$} & \multirow{2}{*}{$\begin{array}{l}\text { Shoot } \\
\text { length }\end{array}$} \\
\hline & & Basal leaf & Middle leaf & Upper leaf & & \\
\hline & & inches & inches & inches & inches & inches \\
\hline None $\ldots \ldots \ldots \ldots \ldots \ldots$ & 0 & 7.0 & 2.5 & 0.5 & 6.0 & 24 \\
\hline 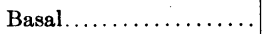 & 21 & 6.5 & 6.5 & 5.5 & 9.5 & 45 \\
\hline Middle $\ldots \ldots \ldots \ldots \ldots \ldots$ & 21 & 6.5 & 2.5 & 7.5 & 9.0 & 58 \\
\hline Upper.............. & 21 & 7.5 & 6.5 & dead & 8.5 & 44 \\
\hline
\end{tabular}

about 6 inehes long (about 2 inches longer than in the first experiment, conducted seven days earlier). The specific activity of the 2,4-D was 10 times greater than in the first experiment, although the dosage was the same$20 \mu \mathrm{g}$. This was important in the counting and chemical identification work, to be presented later.

The results of the second experiment differed only slightly from those of experiment 1. Absorption and export from the lower treated leaf may have been slower than in the first experiment (fig. 9). Migration was upward into the cluster and the actively growing portions of the shoot above 


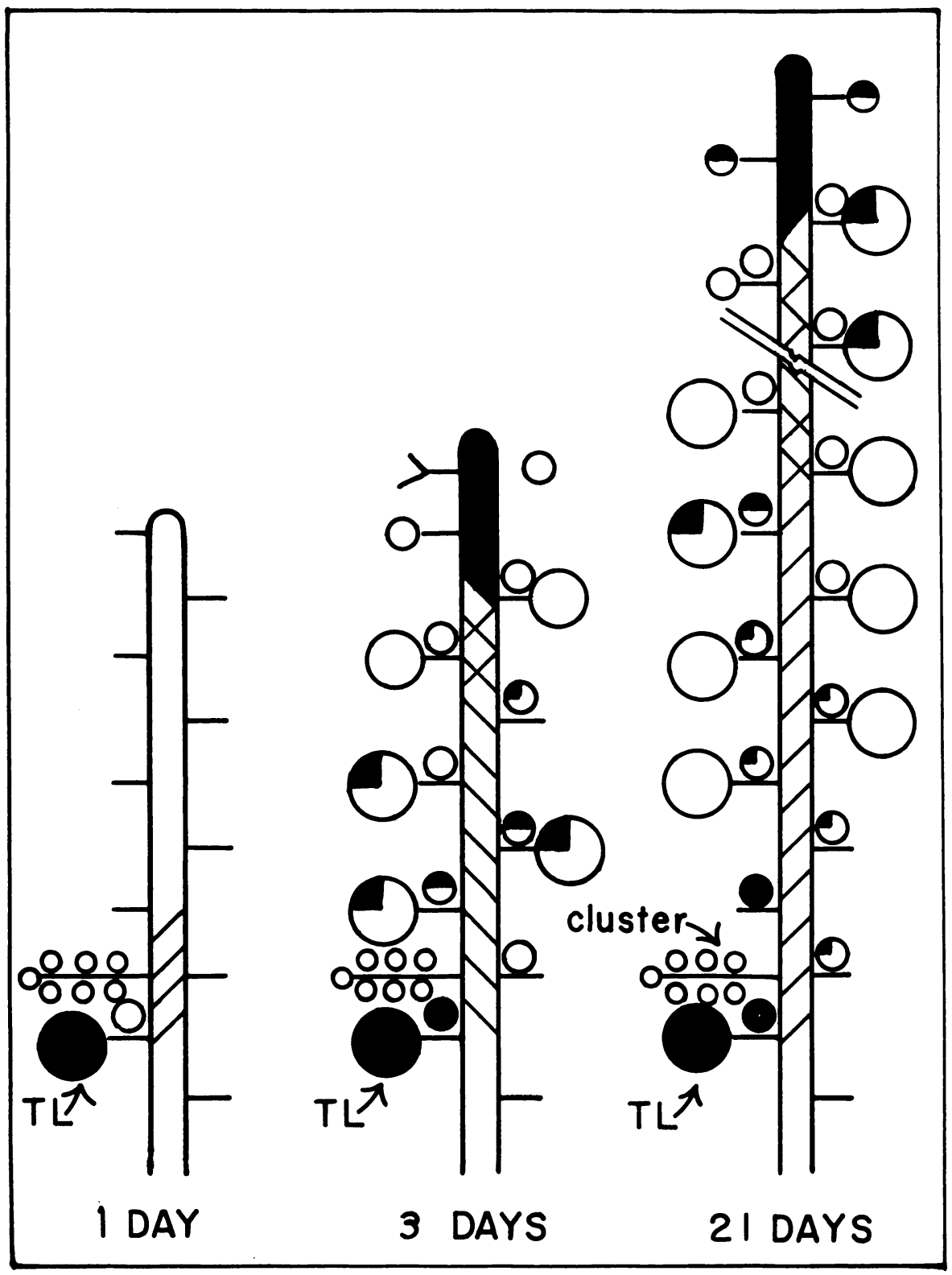

\section{2,4-D LOWER LEAF TREATED}

Fig. 9. Distribution of radioactivity in the Tokay grape shoot one, three, and 21 days after treatment with 2,4-D on May 5, 1959. Treated leaf (TL) (full sized) was first leaf directly beneath cluster. (See "A note on the charts," p. 336.) 


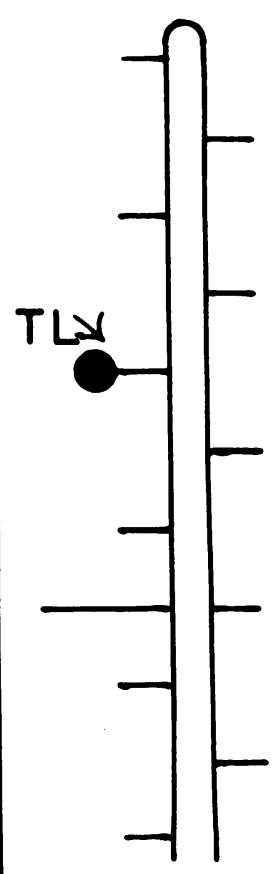

I DAY

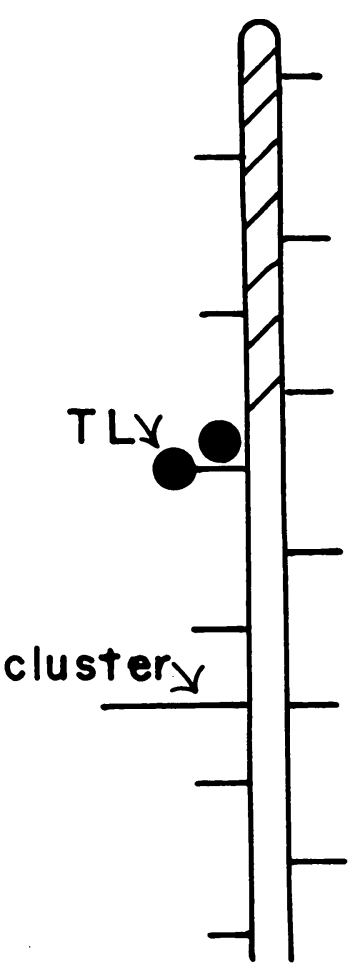

3 DAYS

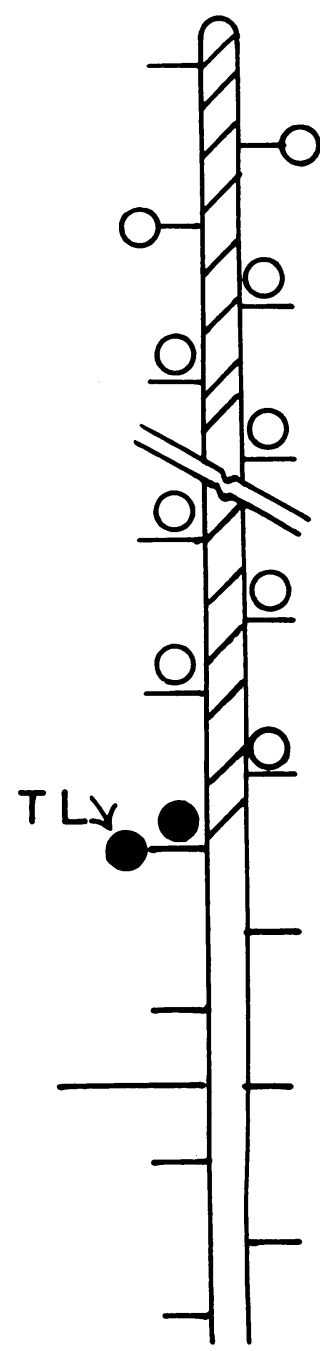

2I DAYS

\section{2,4-D MIDDLE LEAF TREATED}

Fig. 10. Distribution of radioactivity in the Tokay grape shoot one, three, and 21 days after treatment with 2,4-D on May 5, 1959. Treated leaf (TL) (2.5 inches wide) was second leaf directly above cluster. (See "A note on the charts," p. 336.) 


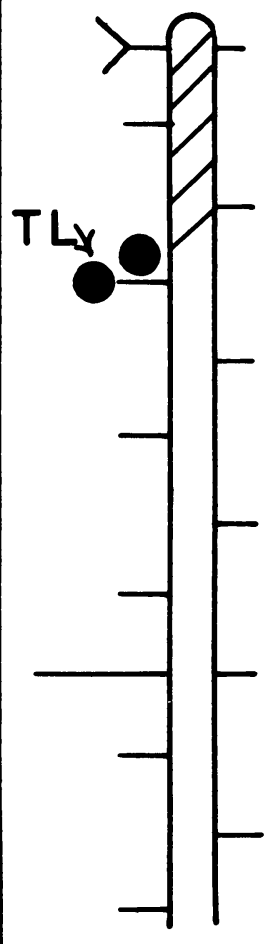

I DAY

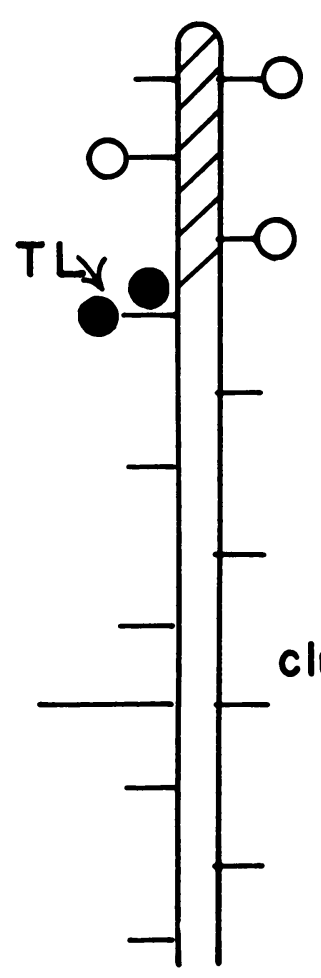

3 DAYS

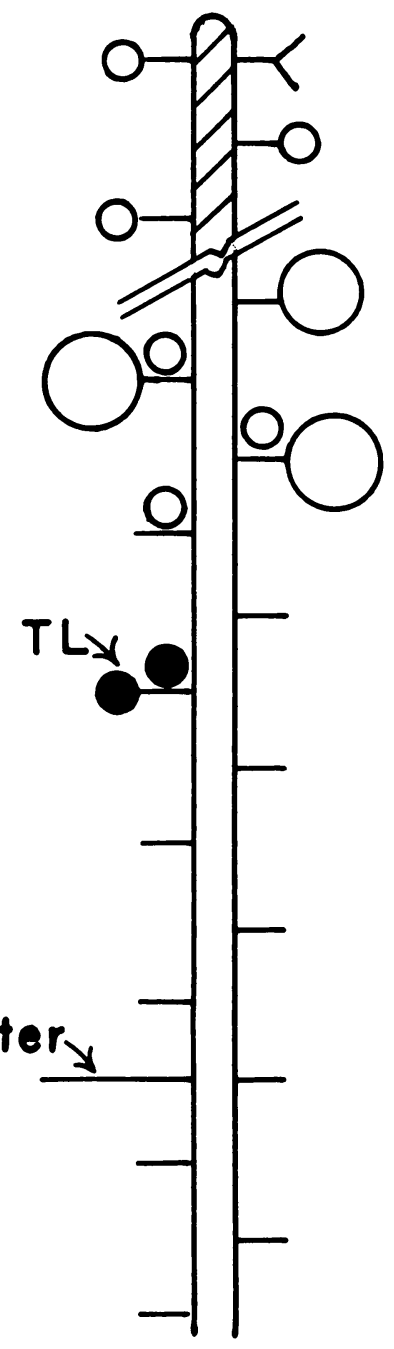

21 DAYS

\section{2,4-D UPPER LEAF TREATED}

Fig. 11. Distribution of radioactivity in the Tokay grape shoot one, three, and 21 days after treatment with 2,4-D on May 5, 1959. Treated leaf (TL) ( 0.5 inch wide) was third leaf directly above cluster. (See "A note on the charts," p. 336.) 
the cluster. If downward movement occurred, it was not apparent, except in one shoot shown in figure 12.

The treatments had scarcely any detectable effect on the mature basal leaves, and the effect on new, expanding leaves was only slight during the 21-day period.

The second leaf directly above the cluster was selected as the middle treated leaf in the second experiment (fig. 10). These leaves, about 2.5 inches wide, were visibly injured by the treatments. No activity (in two out of the three treatments) was apparent outside the treated leaves one day after treatment. Three days after treatment, two out of the three shoots showed traces of activity above the treated leaves. The treated leaves showed some injury at that time, and were folded. Three weeks after treatment, there was activity in the buds above the treated leaf, the shoot apex, and stem, but none in the cluster or shoot below the treated leaf. The greatest activity was in the axillary bud of the treated leaf.

The very small, upper treated leaf was quickly injured (some of the tissues killed) by the $20 \mu \mathrm{g}$ of 2,4-D. Visible activity was discernible in the stem apical to the treated leaves within one day, as well as being fairly concentrated in the axillary bud of the treated leaf (fig. 11). Activity increased, but not greatly, in the entire shoot above the treated leaf three and 21 days following treatment. Since the treated leaf was dead or nearly so, this export was probably physical in nature and not metabolic. Evidently the labeled 2,4-D moved out of the dead tissue of the leaf into the xylem and was moved apically in the transpiration stream.

One variation of experiment 2 compared the effect of lateral location of the leaf with respect to translocation to the clusters (fig. 12). When 2,4-D was applied to a leaf on the opposite side of the stem from the cluster, and basal to it, none moved into the cluster in one day. Some cross-over to the other side of the stem did occur as the distance increased from the point of application. For example, some 2,4-D did go into the second immature leaf and its axillary bud directly apical to the cluster. The "one-sided" translocation above the treated leaves was visible in the stem cross-sections for several nodes. This activity was in the cambium and phloem, but not in the xylem.

\section{Experiment 3}

The third experiment was conducted on May 9, 1960, four days later in the year than in experiment 2. The shoots chosen for study averaged about 26 inches long, which was a trifle longer than those in the second experiment (table 4). Flower clusters averaged 8 inches long. The second leaf above the clusters was 3.5 inches wide rather than 2.5 inches as in experiment 2. Although the differences in shoot or cluster development between experiments 2 and 3 appear to be rather minor, they were associated with a marked difference in the pattern of translocation.

The translocation of 2,4-D and amitrole from the lower treated leaves is shown in figures 13 and 14. These leaves were directly beneath the clusters, as with previous tests. Three days after treatment, translocation was apical in 50 per cent of the shoots; the other 50 per cent showed slight downward movement in addition to the main apical movement. Appreciable activity 

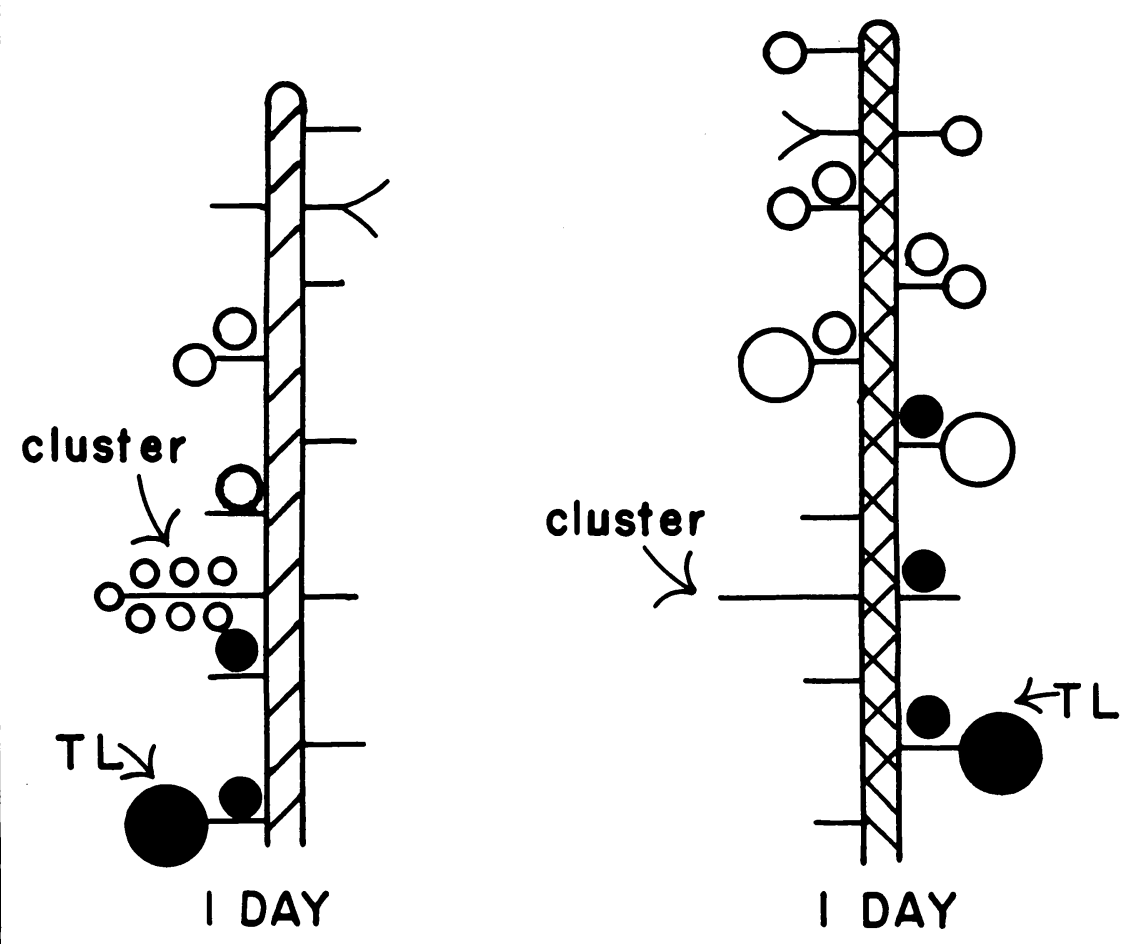

\section{2,4-D LEAF POSITION}

Fig. 12. Distribution of radioactivity in the Tokay grape shoot one day after treatment, as influenced by position of treated leaf. Leaves were treated with labeled 2,4-D on May 5, 1959. (See "A note on the charts," p. 336.) 
TABLE 4

EFFECT OF 2,4-D AND AMITROLE ON LEAF WIDTH, SHOOT AND

CLUSTER LENGTH, AND WEIGHT OF CLUSTERS OF TOKAY

GRAPES AT TIME OF TREATMENT AND 112 DAYS AFTER TREATMENT

(Experiment 3, May 9, 1960)

\begin{tabular}{|c|c|c|c|c|c|c|c|}
\hline \multirow{2}{*}{ Leaf treated } & \multirow{2}{*}{$\begin{array}{c}\text { Chemical } \\
\text { used }\end{array}$} & \multirow{2}{*}{$\begin{array}{l}\text { Number of } \\
\text { days after } \\
\text { treatment }\end{array}$} & \multicolumn{2}{|c|}{ Width of: } & \multirow{2}{*}{$\begin{array}{l}\text { Cluster } \\
\text { length }\end{array}$} & \multirow{2}{*}{$\begin{array}{l}\text { Shoot } \\
\text { length }\end{array}$} & \multirow{2}{*}{$\begin{array}{l}\text { Cluster } \\
\text { weight }\end{array}$} \\
\hline & & & Basal leaf & Upper leaf & & & \\
\hline & & & inches & inches & inches & inches & $g m$ \\
\hline None... & none & 0 & 6.5 & 3.5 & 8.0 & 26 & 6 \\
\hline None.. & none & 112 & 6.0 & 7.0 & 10.0 & 55 & 590 \\
\hline Basal.. & $2,4-D$ & 112 & 6.0 & 7.0 & 11.0 & 60 & 476 \\
\hline Upper. & 2,4-D & 112 & 6.0 & 6.0 & 10.5 & 60 & 380 \\
\hline Basal.. & amitrole & 112 & 6.5 & 7.0 & 9.5 & 70 & 360 \\
\hline Upper.. & amitrole & 112 & 6.5 & 6.5 & 10.5 & 67 & 530 \\
\hline
\end{tabular}

was present in the clusters, axillary buds, tendrils, stems, and shoot apices.

The total activity in the shoots resulting from treatment of the lower leaves with 2,4-D was considerably greater at 23 days after treatment than at three days (fig. 13). However, there was no marked change in activity of amitrole in the shoots between three and 23 days after treatment (fig. 14). This indicates a limited period of absorption and translocation of amitrole. Fading of the autoradiographs between 23 and 112 days after treatment suggests that the radioactive products were slowly translocated somewhere, or else lost as labeled $\mathrm{CO}_{2}$. Evidence in table 8 (p. 358) suggests that traces of activity were probably translocated to the clusters.

The distribution patterns of the two chemicals were appreciably different in the shoots. The 2,4-D was concentrated in the stem portion of the shoot apex and in tendrils, axillary buds, youngest immature leaves, and flower clusters. The distribution pattern with amitrole suggests that there was little apical translocation beyond three days after treatment, since only traces of activity were evident in the shoot apex and tendrils 23 days after treatment.

The translocation pattern of both compounds altered between three (fig. 2, p. 330) and 23 days (figs. 3 and 4, pp. 331 and 332) after treatment. In the latter case activity was present in the stems below the treated leaves. The buds were dormant, which may account for lack of activity in those tissues below the treated leaves. Much translocation was in the apical direction from the lower treated leaves to the flower clusters, especially in the case of 2,4-D, as may be suggested from the data shown in table 7 (p. 358).

At harvest, 112 days after treatment, only traces of radioactivity were evident in the shoot apices when 2,4-D treatment was on the lower leaves, and no activity at all was evident from similar treatment with amitrole. Most buds (or shoot apices that developed from those buds) showed no activity. Slight activity was present in the stems below the treated leaves. Differences in the distribution patterns of 2,4-D and amitrole were mainly of degree, the 2,4-D being more generally distributed at this time.

No visible effects of treatment with either 2,4-D or amitrole were evident 23 days after treatment. This contrasted with the results with 2,4-D in 


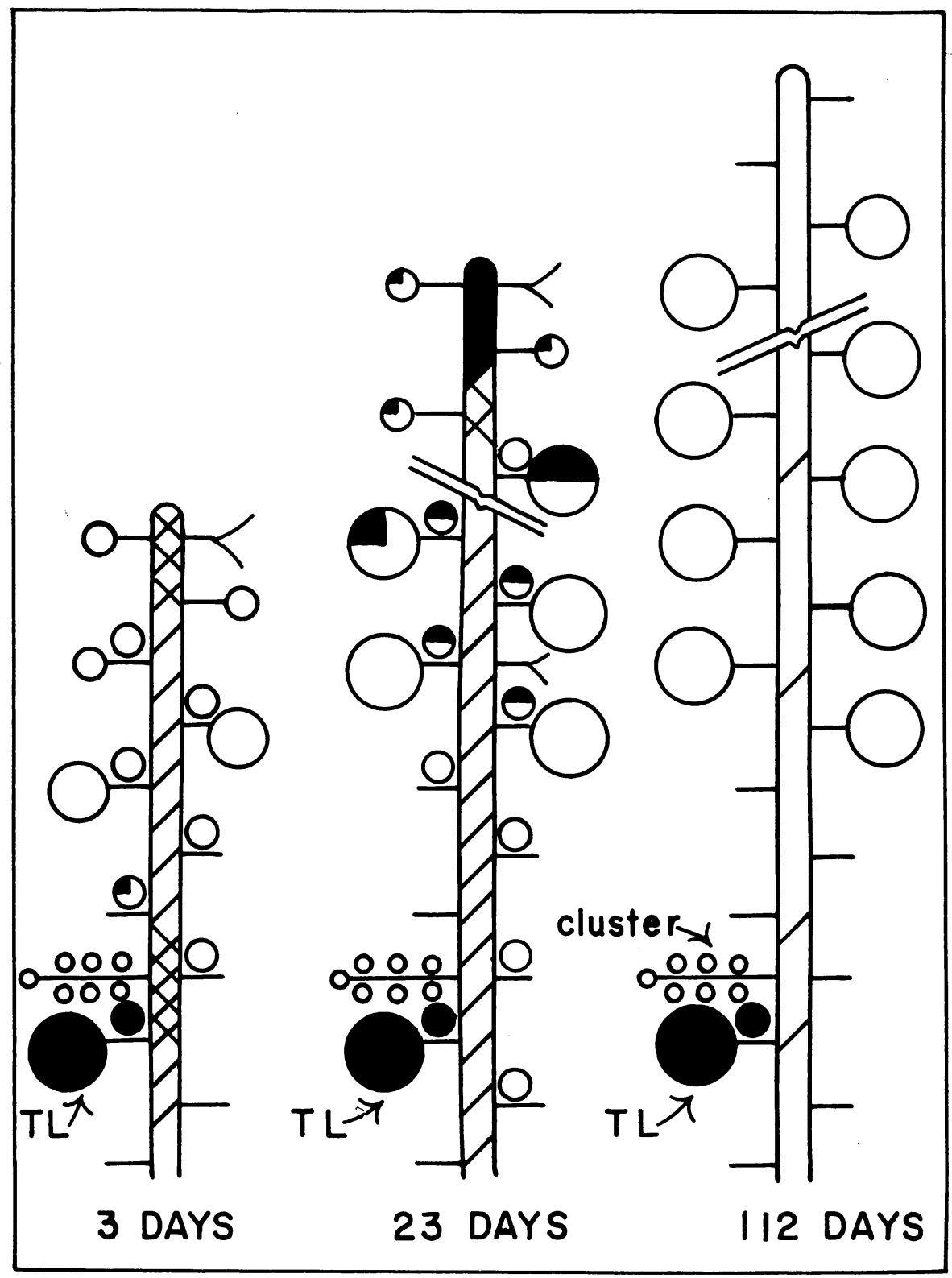

\section{2,4-D LOWER LEAF TREATED}

Fig. 13. Distribution of radioactivity in the Tokay grape shoot three, 23, and 112 days after treatment with labeled 2,4-D on May 9, 1960. Treated leaf (TL) (full sized) was first leaf directly beneath cluster. (See "A note on the charts," p. 336.) 


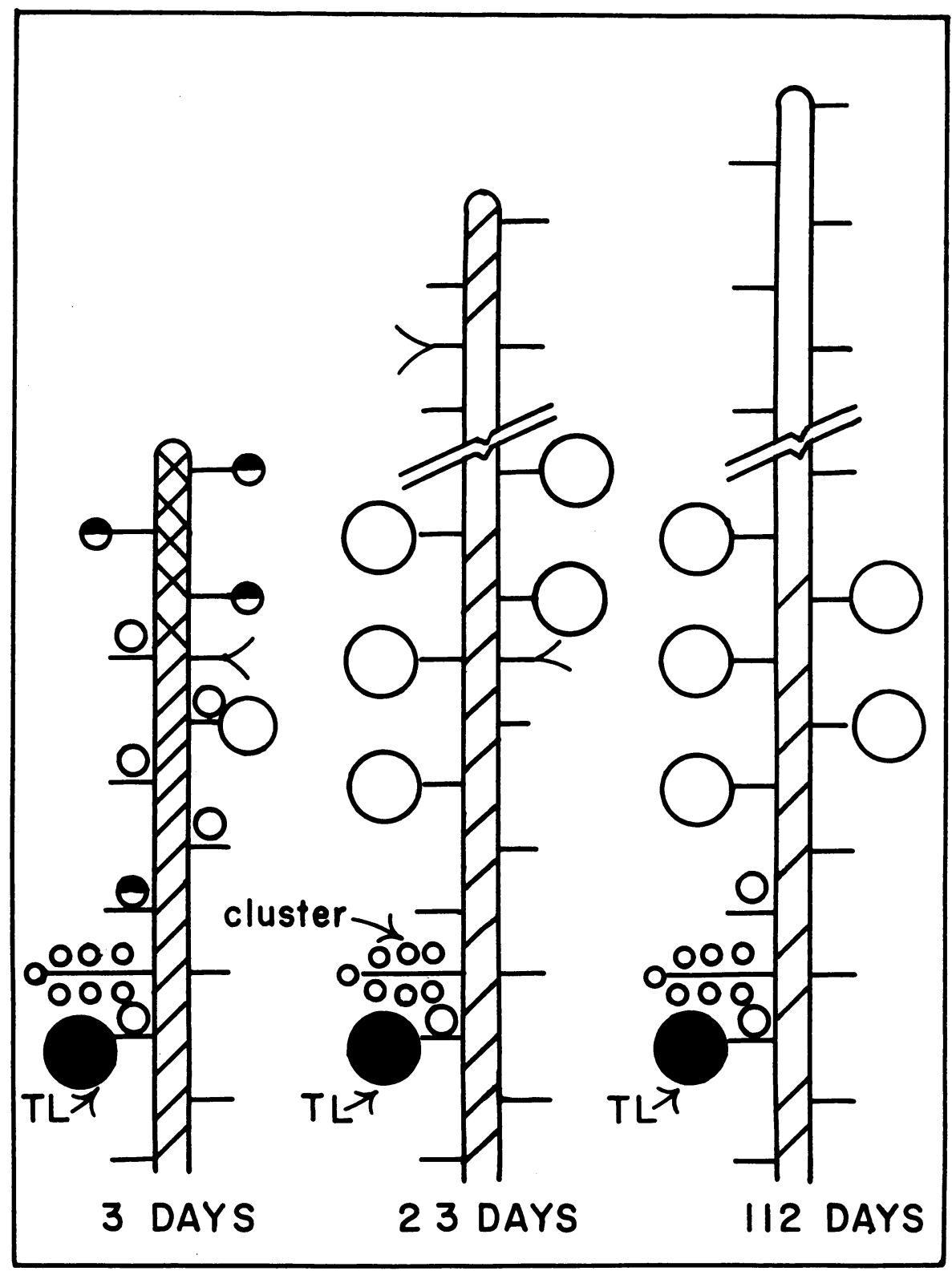

\section{AMITROLE LOWER LEAF TREATED}

Fig. 14. Distribution of radioactivity in the Tokay grape shoot three, 23, and 112 days after treatment with labeled amitrole on May 9, 1960. Treated leaf (TL) (full sized) was first leaf directly beneath cluster. (See "A note on the charts," p. 336.) 


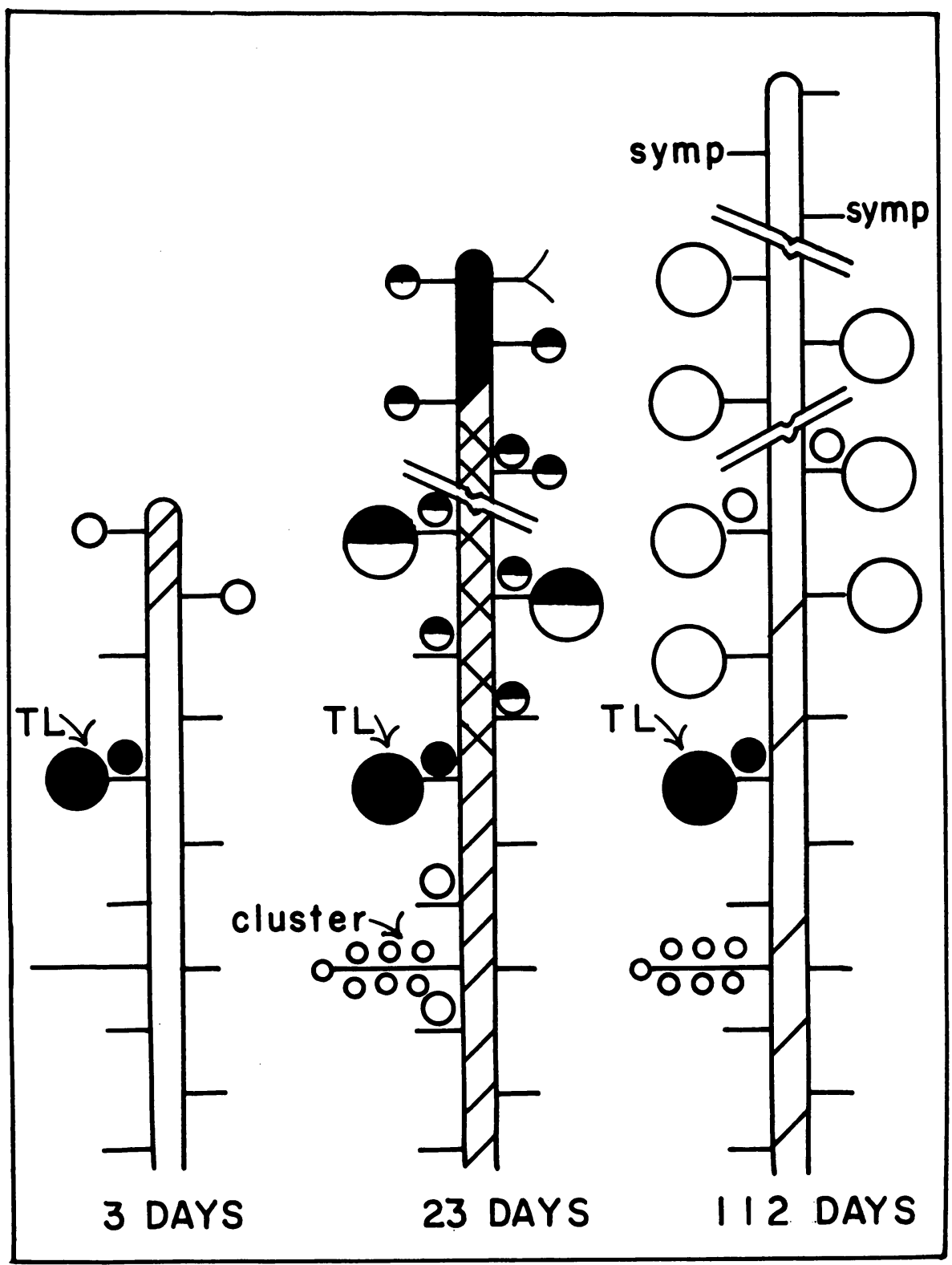

\section{2,4-D UPPER LEAF TREATED}

Fig. 15. Distribution of radioactivity in the Tokay grape shoot three, 23, and 112 days after treatment with labeled 2,4-D on May 9, 1960. Treated leaf (TL) (3.5 inches wide) was second leaf directly above cluster. (See "A note on the charts," p. 336.) 
experiment 1 and, to a lesser extent, in experiment 2, where leaf malformation occurred. Effects due to amitrole were not evident 112 days after treatment, but this was not the case with 2,4-D. Small, malformed leaves were present, but these contained only traces of radioactivity, and others may have been free of it. The outstanding effect of 2,4-D treatment of the leaves below the clusters was death of the clusters on two out of the three shoots, between 23 and 112 days after treatment. The radioactivity in the surviving cluster is shown in table 7 (p. 358).

The translocation of 2,4-D and amitrole from the leaves above the clusters is shown in figures 15 and 16, respectively; the second leaves directly above the clusters were treated.

Translocation out of the leaves above the clusters three days after treatment appeared to be related to width of the leaves at time of treatment. In one branch, the 2,4-D-treated leaf was 2.75 inches in width, and exported no radioactivity in three days; on the other two branches the treated leaves were 3 inches wide, and those did export small quantities of activity. The $20-\mu \mathrm{g}$ application of 2,4-D appeared to have very little if any effect on these leaves, in contrast to a definite effect produced on the same leaves in experiment 2 , and leaves of the same width in experiment 1 . With the amitrole treatment, one leaf 2.5 inches wide exported no activity in the three-day period; on the other hand, one leaf 3.5 inches wide did export appreciable activity during that period.

Translocation was strictly apical during the first three days after treatment with 2,4-D (fig. 15) and amitrole (fig. 16). The stem cross-sections immediately below the treated leaves were generally radioactive. Most flow was on the side of the stem of the treated leaf, as may be noted from the activity in the buds. The total export of amitrole during this period was considerably greater than that of 2,4-D from the upper treated leaves; however, the width of the leaf for the 2,4-D treatment was 3 inches, as compared with a $3 \frac{1}{2}$-inch leaf for the amitrole treatment. As noted above, the size of a leaf has a marked bearing on whether it is an importing or an exporting leaf. In addition, 2,4-D has already been shown to have a temporary inhibitory effect on the development of polar transport out of immature leaves. This factor may have been negligible in this experiment, however, since the leaves were not appreciably visibly affected by the treatment. The clusters were free of activity with both 2,4-D and amitrole treatments since no basal movement occurred within the three-day period.

Movement of both 2,4-D and amitrole from the leaves above the clusters shifted between three and 23 days after treatment-as noted for the lower treated leaves. Some of the translocation from the treated leaves appears to have become basal in direction, with much of the radioactivity going to the flower clusters. However, some labeled 2,4-D moved past the clusters down the stems, but little, if any, amitrole did so.

The patterns of distribution of radioactivity from the treatments with 2,4-D and amitrole were similar to those obtained from the lower treated leaves. The activity in the shoot apices was greater, probably because the early movement was apical, thus reducing the activity going to the clusters. Again, little if any translocation of amitrole out of the upper treated leaves appears to have occurred beyond three days following treatment; this con- 


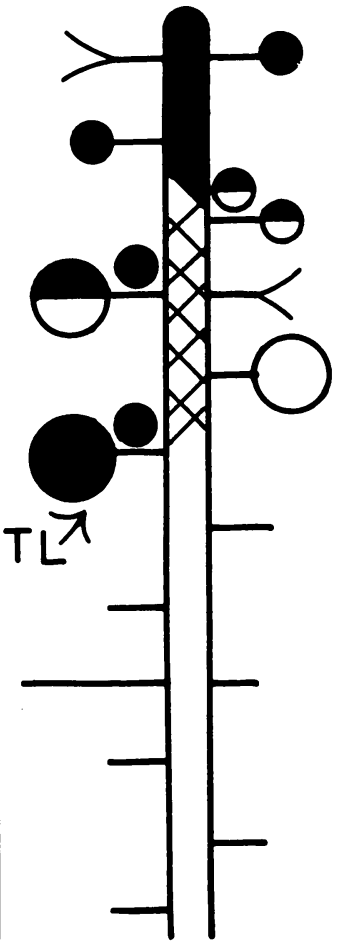

3 DAYS

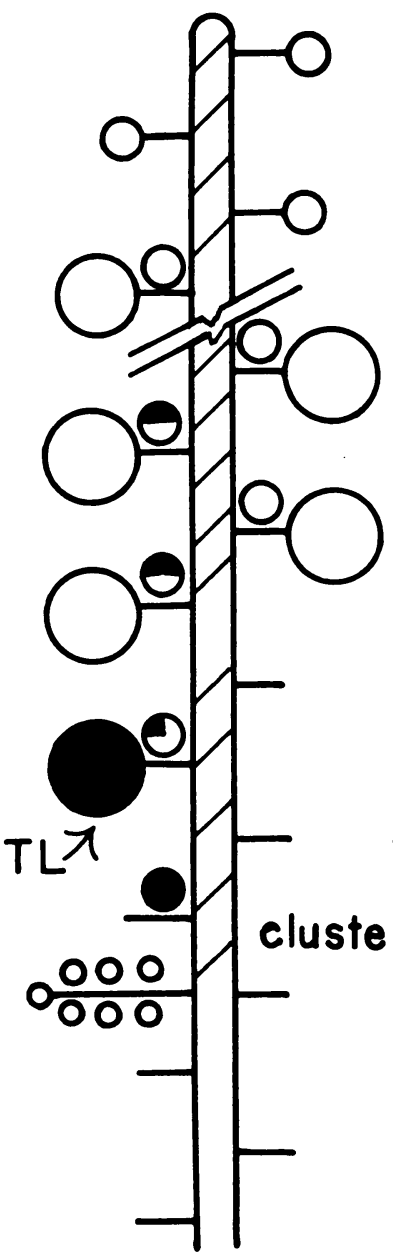

23 DAYS

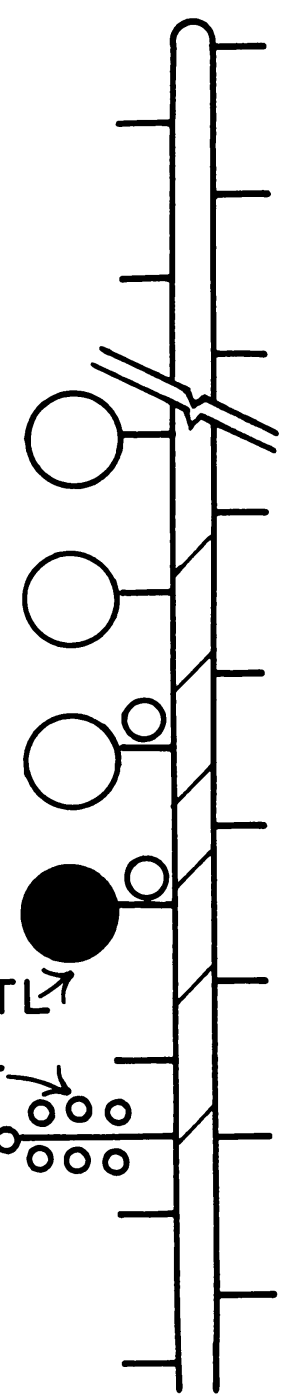

112 DAYS

\section{AMITROLE UPPER LEAF TREATED}

Fig. 16. Distribution of radioactivity in the Tokay grape shoot three, 23, and 112 days after treatment with labeled amitrole on May 9, 1960. Treated leaf (TL) (3.5 inches wide) was second leaf directly above cluster. (See "A note on the charts," p. 336.) 
clusion is also supported by the results in table 6 (p. 357). Again, the situation with 2,4-D was quite different in that considerable activity was exported between three and 23 days after treatment. Only one of the three shoots treated with 2,4-D had any activity in a bud below the cluster and none of the three shoots treated with amitrole had activity in any buds below the clusters.
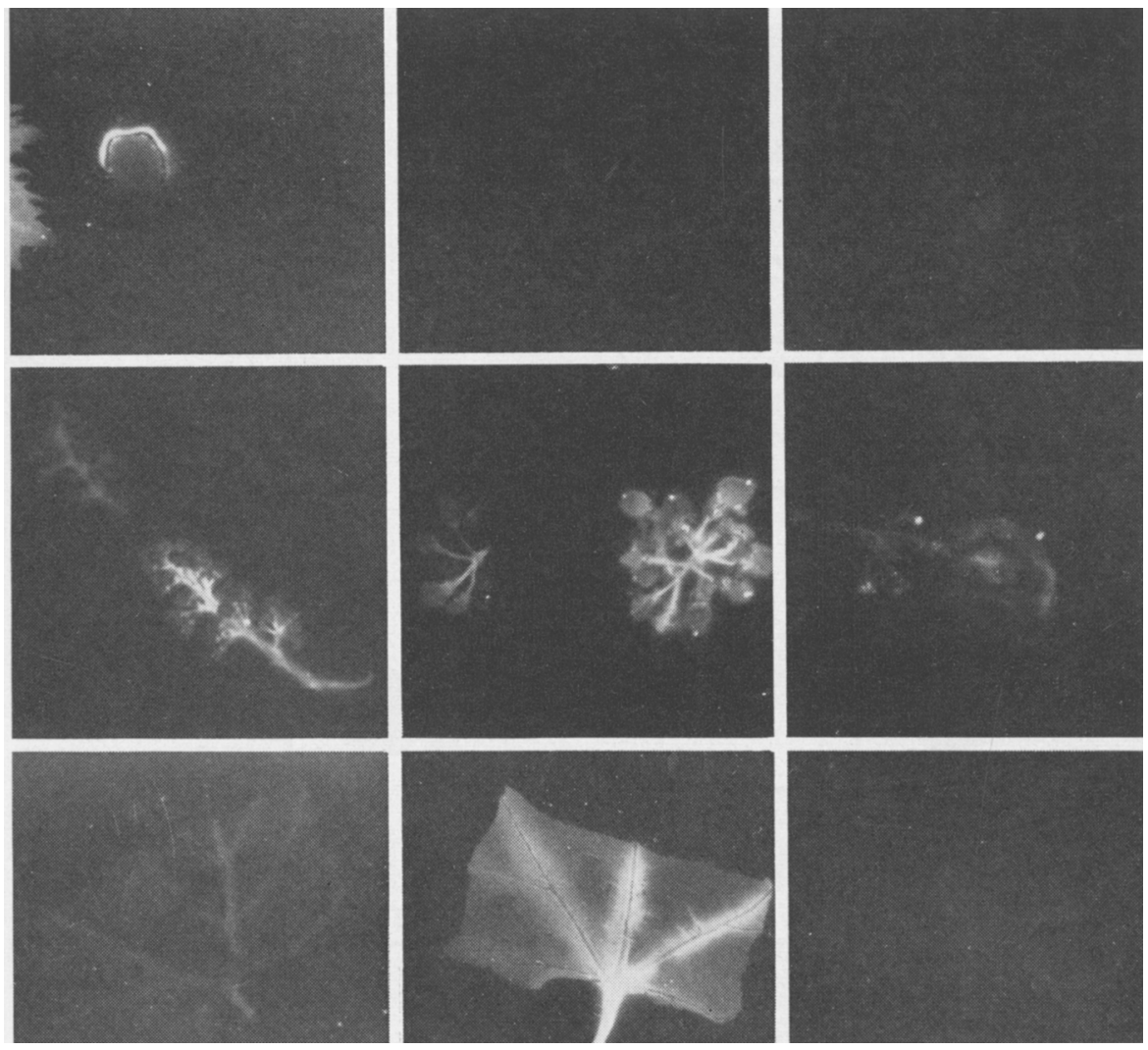

Fig. 17. Effect of treating first leaf below cluster on radioactivity in stem cross-sections, cluster, and leaves three, 23, and 112 days after treatment with 2,4-D on May 9, 1960. Top to bottom: stem-a cross-section of first internode below clusters; cluster-a branch; leaf-fifth to seventh leaf above clusters. Autoradiographs on left were from samples obtained three days after treatment; center, 23 days after treatment; right, 112 days after treatment.

By far the greatest accumulation of activity in the stem above the cluster occurred in one of the 2,4-D-treated shoots which broke off just five nodes above the treated leaf (fig. 17). The accumulation in the stem above the treated leaf was high, and that in the tendrils was even more intense. The break did appear to initiate a very strong apical sink which reduced radioactivity in the cluster to about one-third (1,800 counts per minute, equivalent to $0.36 \mu \mathrm{g}$ of 2,4-D) that of the other two clusters on shoots which were not broken off $(6,800$ and 7,000 counts per minute, or about $1.4 \mu \mathrm{g} 2,4-\mathrm{D})$. 


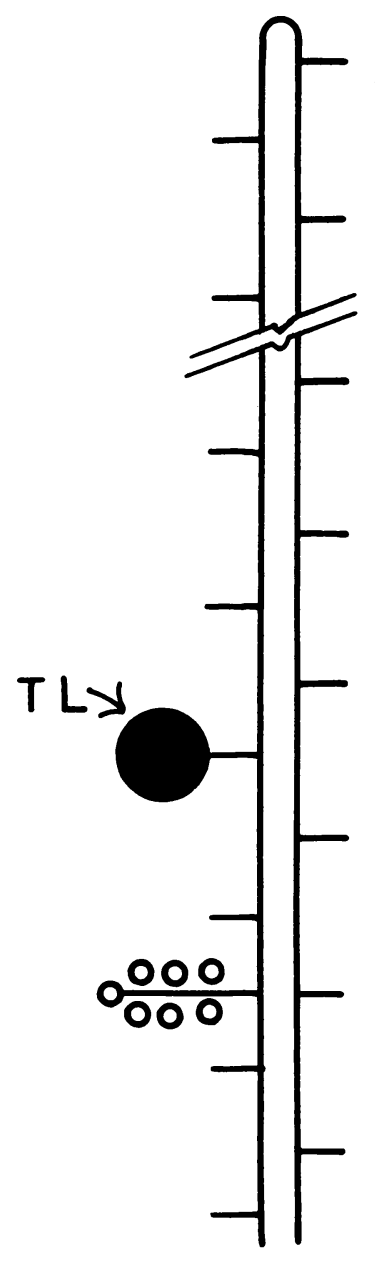

3 DAYS

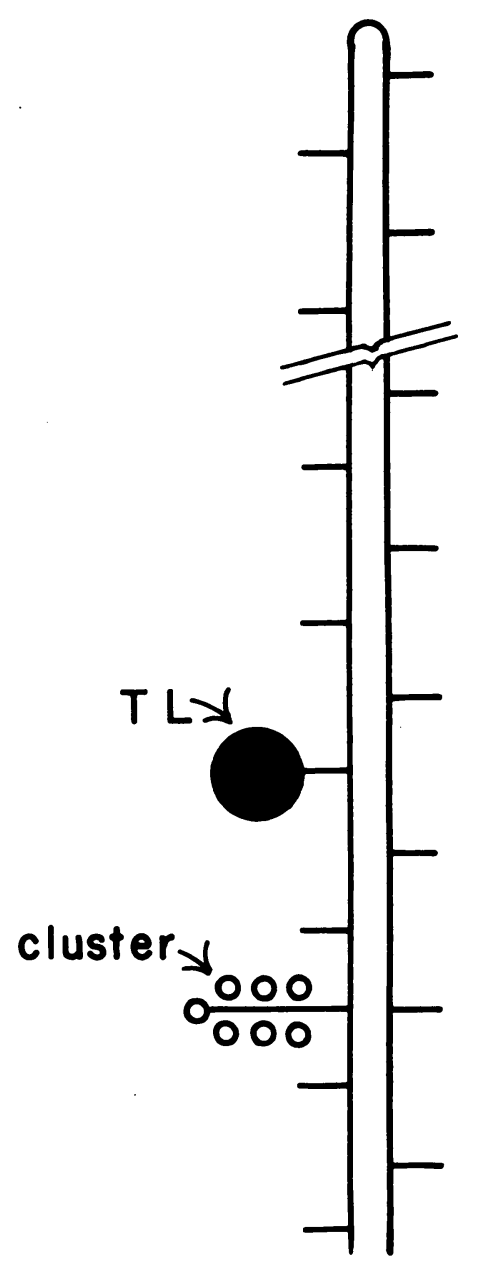

38 DAYS

\section{2,4-D OR AMITROLE}

Fig. 18. Distribution of radioactivity in the shoots of the Tokay grape three and 38 days after treatment with labeled 2,4-D or amitrole on July 26, 1960. Treated leaf (TL) (full sized) was second leaf above cluster. Same distribution was observed when first leaf below cluster was treated. There was no detectable activity except in the cluster with the 2,4-D treatment, and only a possible trace with amitrole. 
Activity in the shoots 112 days after treatment of the upper leaves (second leaf above the clusters) was similar to that obtained from the lower leaf treatments. The shoots' apices showed no activity from either 2,4-D or amitrole. Small leaves near the apices of the shoots or on lateral branches were malformed by 2,4-D, although their radioactivity was insufficient to be detected. In the case of the 2,4-D treatment, some activity was present in the stem below the cluster, but none was evident from the amitrole treatment; the same distribution pattern was apparent 23 days after treatment.

\section{Experiment 4}

Applications to leaves were made on July 26, 1960, when the clusters had attained about 50 per cent of their maximum growth (by weight). Results are shown in table 5 . The average berry weight was $1.2 \mathrm{gm}$ and the total

TABLE 5

EFFECT OF 2,4-D AND AMITROLE ON LEAF WIDTH, SHOOT AND CLUSTER LENGTH, AND CLUSTER WEIGHT OF TOKAY GRAPES

(Experiment 4, July 26, 1960)

\begin{tabular}{|c|c|c|c|c|c|c|}
\hline \multirow{2}{*}{ Leaf treated } & \multirow{2}{*}{$\begin{array}{l}\text { Number of } \\
\text { days after } \\
\text { treatment }\end{array}$} & \multicolumn{2}{|c|}{ Width of : } & \multirow{2}{*}{$\begin{array}{l}\text { Cluster } \\
\text { length }\end{array}$} & \multirow{2}{*}{$\begin{array}{l}\text { Shoot } \\
\text { length }\end{array}$} & \multirow{2}{*}{$\begin{array}{l}\text { Cluster } \\
\text { weight }\end{array}$} \\
\hline & & Basal leaf & Upper leaf & & & \\
\hline & & inches & inches & inches & inches & $g m$ \\
\hline None. & 0 & 6.5 & 7 & 10 & 67 & 380 \\
\hline None.. & 38 & 6.5 & 7 & 10 & 65 & 550 \\
\hline Basal*. & 38 & 6.5 & 7 & 10 & 65 & 550 \\
\hline Upper*... & 38 & 6.5 & 7 & 10 & 65 & 550 \\
\hline
\end{tabular}

* Approximately the same data for 2,4-D and amitrole.

soluble solids, 5.8 per cent. Collections were made three and 38 days after treatment. The total soluble solids had increased to 15 per cent and the average berry weight to $2.4 \mathrm{gm}$ by 38 days.

No radioactivity was detectable anywhere in the shoots, except in the fruit clusters (fig. 18). The localization of radioactivity contrasted markedly with the results obtained during the vigorous vegetative growth period, when accumulation in the clusters was especially marked for 2,4-D.

One variation of this test was enclosure of 2,4-D- and amitrole-treated leaves in translucent polyethylene bags during the three-day period of the experiment. Appreciable free water collected on the insides of the bags, but the leaves were not injured. A possible trace of activity appeared in the stem between the treated leaf and the fruit. The environment produced by the polyethylene bag greatly enhanced the absorption and translocation of amitrole within the shoot (table 8, p. 358, and fig. 19), but had little influence on the movement of $2,4-\mathrm{D}$.

\section{Loss of Activity from Treated Leaves}

The loss of radioactivity from treated leaves during the various experiments is shown in table 6 . The results are averages of two or three leaves, but only the general trends should be considered. 
Loss of activity from treated leaves may have resulted from (1) translocation out of the treated leaves, (2) decomposition of the compounds and loss as $\mathrm{CO}_{2}$, and (3) physical loss of the compounds in one way or another. Some loss in experiment 3 could have resulted from a rain which occurred about two weeks after the test was put out.

Loss of radioactivity from the leaves treated with 2,4-D appears to be related to leaf size (width or weight, as previously mentioned). Loss was least from the small, immature leaves. Such leaves were importing assimi-

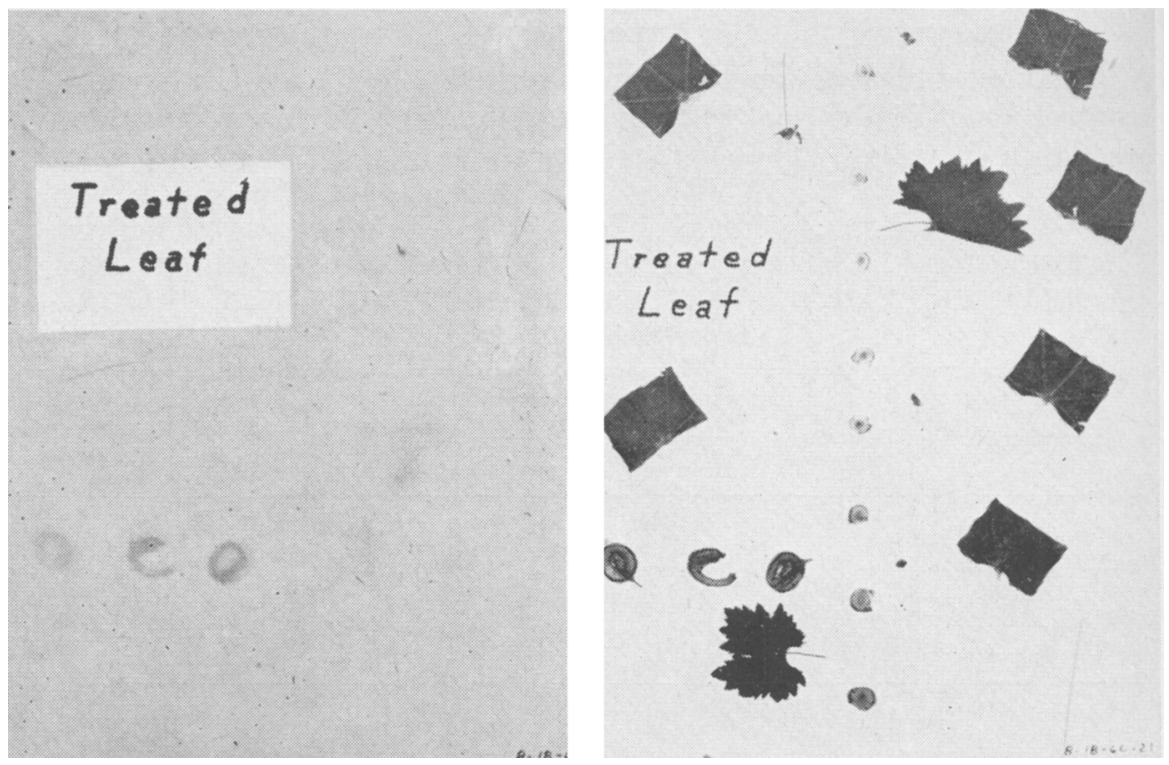

Fig. 19. Second leaf above cluster was treated with amitrole and then covered with a polyethylene bag on July 26, 1960. Collection was made three days later. Autoradiographs, left; mounted specimens, right. Labeling was slight, except in the fruit.

lates when treated, so that a period of time elapsed before they became exporting leaves. Thus, 2,4-D and amitrole would have more time to become decomposed and complexed in these leaves than in the leaves that were exporting at the time of treatment. Of even greater importance was the fact that leaf injury from the 2,4-D was related to leaf size-a factor not involved with amitrole, which was visibly completely noninjurious to the leaves.

The pattern of amitrole loss from treated leaves was quite different from that of the 2,4-D. Essentially all of the loss took place within three days following treatment, except for the leaves treated on July 26. Even here, there was very little loss of activity after the three-day period. These results suggest that amitrole rapidly becomes immobilized within the treated leaves, as already suggested by the autoradiographs. Loss of amitrole from the treated leaves was related to leaf weight-mature leaves exported more than did immature ones (experiment 3 ). This was also true with 2,4-D, but to much less extent.

Marked losses of radioactivity from the treated leaves occurred with both 
2,4-D and amitrole during the course of experiment 4 . Some of the activity went to the fruit, but what happened to the balance is uncertain. The leaves were several months old, so it is possible that some of the activity flaked off with the old cuticle. That this may have occurred is further suggested from the changes in radioactivity of the leaves that were covered with poly-

TABLE 6

LOSS OF RADIOACTIVITY FROM LEAVES OF TOKAY GRAPES TREATED WITH 2,4-D AND AMITROLE ON VARIOUS DATES

\begin{tabular}{|c|c|c|c|c|c|}
\hline \multirow{3}{*}{ Date treated } & \multirow{3}{*}{$\begin{array}{l}\text { Treatment } \\
\text { period }\end{array}$} & \multicolumn{4}{|c|}{ Leaf position } \\
\hline & & \multicolumn{2}{|c|}{ Below cluster } & \multicolumn{2}{|c|}{ Above cluster } \\
\hline & & $\begin{array}{c}\text { Loss of } \\
\text { radioactivity }\end{array}$ & $\begin{array}{l}\text { Weight of } \\
\text { leaf (dry) }\end{array}$ & $\begin{array}{c}\text { Loss of } \\
\text { radioactivity }\end{array}$ & $\begin{array}{l}\text { Weight of } \\
\text { leaf (dry) }\end{array}$ \\
\hline & days & per cent & $g m$ & per cent & $g m$ \\
\hline \multicolumn{6}{|c|}{$2,4-\mathrm{D}$} \\
\hline \multirow[t]{3}{*}{$4 / 28 / 59$} & 1 & 10 & 1.6 & 10 & 0.4 \\
\hline & 3 & 39 & 1.8 & 20 & 0.4 \\
\hline & 21 & 80 & 2.0 & 39 & 0.7 \\
\hline \multirow[t]{3}{*}{$5 / 5 / 59 \ldots$} & 1 & 9 & 1.6 & 5 & 0.2 \\
\hline & 3 & 8 & 2.0 & 0 & 0.2 \\
\hline & 21 & 68 & 1.6 & 11 & 0.3 \\
\hline \multirow[t]{3}{*}{$5 / 9 / 60 \ldots \ldots \ldots \ldots \ldots \ldots \ldots \ldots$} & 3 & 75 & 1.5 & 68 & 0.5 \\
\hline & 23 & 99 & 1.4 & 89 & 0.8 \\
\hline & 112 & 99 & 1.8 & 85 & 1.8 \\
\hline \multirow[t]{3}{*}{$7 / 26 / 60 \ldots$} & 3 & 60 & 1.6 & 60 & 2.0 \\
\hline & 3 (leaf bagged) & .. & $\ldots$ & 15 & 2.4 \\
\hline & 38 & 97 & 1.6 & 99 & 2.2 \\
\hline \multicolumn{6}{|c|}{ Amitrole } \\
\hline \multirow[t]{3}{*}{$5 / 9 / 60$} & 3 & 80 & 1.8 & 50 & 0.6 \\
\hline & 23 & 90 & 1.6 & 54 & 0.2 \\
\hline & 112 & 82 & 2.1 & 20 & 1.9 \\
\hline \multirow[t]{3}{*}{$7 / 26 / 60 \ldots \ldots \ldots \ldots \ldots \ldots \ldots \ldots$} & 3 & 90 & 1.6 & 90 & 1.6 \\
\hline & 3 (leaf bagged) & . & .. & 40 & 1.8 \\
\hline & 38 & 92 & 1.6 & 92 & 1.8 \\
\hline
\end{tabular}

ethylene bags (table 6). The translocation of amitrole from bagged leaves to the fruit clusters (fig. 19, table 8) was far greater than from leaves that were not covered (fig. 18, table 8). In spite of the greater translocation of amitrole from the treated leaf, it lost only 40 per cent of its radioactivity during the three-day period, as compared with a loss of 90 per cent from the noncovered leaves (table 6).

\section{Activity in Flowers and Fruit}

The radioactivity in the ethanol extracts and residues of the fruit clusters is shown in tables 7 and 8 . The ethanol extract was studied further, to de- 
termine the approximate quantities of 2,4-D and amitrole remaining in the clusters.

TABLE 7

ETHANOL-SOLUBLE, ETHYL ETHER-SOLUBLE, AND INSOLUBLE RADIOACTIVITY IN FLOWER AND FRUIT CLUSTERS OF TOKAY GRAPES TREATED WITH 2,4-D

\begin{tabular}{|c|c|c|c|c|c|c|c|}
\hline \multirow{3}{*}{$\begin{array}{l}\text { Number of } \\
\text { days after } \\
\text { treatment }\end{array}$} & \multirow{3}{*}{$\begin{array}{c}\text { Date } \\
\text { treated }\end{array}$} & \multicolumn{6}{|c|}{ Total radioactivity in clusters, in counts per minute* } \\
\hline & & \multicolumn{3}{|c|}{ First leaf below cluster treated } & \multicolumn{3}{|c|}{ Second leaf above cluster treated } \\
\hline & & $\begin{array}{l}\text { Ethanol- } \\
\text { soluble }\end{array}$ & $\begin{array}{l}\text { Ether- } \\
\text { soluble }\end{array}$ & Residue & $\begin{array}{c}\text { Ethanol- } \\
\text { soluble }\end{array}$ & $\begin{array}{l}\text { Ether- } \\
\text { soluble }\end{array}$ & Residue \\
\hline & \multirow{4}{*}{$5 / 5 / 59$} & c.p.m. & c.p.m. & c.p.m. & c.p.m. & c.p.m. & c.p.m. \\
\hline 1. & & 0 & 0 & 0 & 0 & 0 & 0 \\
\hline 3. & & 3,500 & $2,000 \dagger$ & 600 & 0 & 0 & 0 \\
\hline $21 \ldots \ldots \ldots$ & & 7,000 & $4,000 \dagger$ & 800 & 0 & 0 & 0 \\
\hline 3. & \multirow[t]{3}{*}{$5 / 9 / 60$} & 2,000 & 1,800 & 59 & 0 & 0 & 0 \\
\hline 23. & & 6,000 & 6,000 & 470 & 2,000 & 2,000 & 230 \\
\hline $112 \ldots \ldots \ldots \ldots$ & & $3,000 \ddagger$ & $4,500 \ddagger$ & 4,500 & 4,200 & 4,000 & 4,000 \\
\hline $3 \ldots \ldots$ & \multirow[t]{2}{*}{$7 / 26 / 60$} & 0 & 700 & 0 & 700 & 700 & 0 \\
\hline $38 \ldots \ldots \ldots$ & & 0 & 800 & 0 & 0 & $\ldots$ & 0 \\
\hline
\end{tabular}

* 5,750 c.p.m. equal $1 \mu \mathrm{g}$ of $2,4-\mathrm{D}$.

$\dagger$ Imperfect recovery.

$\ddagger$ Analyses of only one cluster; the other two clusters died, evidently due to excessive 2,4-D.

TABLE 8

THE ETHANOL-SOLUBLE, CATION RESIN-EXCHANGEABLE PORTION OF

THE ETHANOL EXTRACT, AND RESIDUE RADIOACTIVITY IN THE FLOWER AND FRUIT CLUSTERS OF TOKAY GRAPES TREATED WITH AMITROLE

\begin{tabular}{|c|c|c|c|c|c|c|c|}
\hline \multirow{3}{*}{$\begin{array}{l}\text { Number of } \\
\text { days after } \\
\text { treatment }\end{array}$} & \multirow{3}{*}{$\begin{array}{c}\text { Date } \\
\text { treated }\end{array}$} & \multicolumn{6}{|c|}{ Total radioactivity in clusters, in counts per minute ${ }^{*}$} \\
\hline & & \multicolumn{3}{|c|}{ First leaf below cluster treated } & \multicolumn{3}{|c|}{ Second leaf above cluster treated } \\
\hline & & $\begin{array}{c}\text { Ethanol- } \\
\text { soluble }\end{array}$ & $\begin{array}{l}\text { Cation- } \\
\text { exchange }\end{array}$ & Residue & $\begin{array}{l}\text { Ethanol- } \\
\text { soluble }\end{array}$ & $\begin{array}{c}\text { Cation- } \\
\text { exchange }\end{array}$ & Residue \\
\hline & \multirow{4}{*}{$5 / 9 / 60$} & c.p.m. & c.p.m. & c.p.m. & c.p.m. & c.p.m. & c.p.m. \\
\hline 23 . & & 283 & .. & 1,012 & 0 & .. & 0 \\
\hline 23 . & & 110 & 0 & 1,002 & 23 & 0 & 187 \\
\hline 112. & & 0 & 0 & 1,656 & 0 & 0 & 900 \\
\hline $3 \ldots \ldots$ & \multirow{3}{*}{$\begin{array}{c}7 / 26 / 60 \\
\text { (leaf bagged) }\end{array}$} & 0 & 0 & 1,000 & 0 & 0 & 1,000 \\
\hline $3 \ldots \ldots \ldots$ & & .. & .. & $\ldots \ldots$ & 5,000 & 1,728 & 7,000 \\
\hline $38 \ldots \ldots \ldots \ldots$ & & 0 & 0 & 1,000 & 0 & 0 & 1,000 \\
\hline
\end{tabular}

* 950 c.p.m. equal $1 \mu \mathrm{g}$ of amitrole.

Most of the radioactivity from the 2,4-D treatments was ethanol-soluble for the first 21 to 23 days. A gradual conversion of the ethanol-soluble fraction into ethanol-insoluble substances appears to have occurred during the 112-day period in experiment 3. After 112 days, about one-half of the radioactivity was ethanol-insoluble in the fruit clusters. 
The radioactive materials from the amitrole treatments appeared to be largely ethanol-insoluble, with the exception of the result obtained in experiment 4 . In this test, the fruit clusters from the amitrole-treated leaf that was covered with a polyethylene bag contained an appreciable quantity of ethanol-soluble radioactivity, approximately one-third of which was cation exchangeable.

Careful purification of the ethanol extracts of 2,4-D treatments appeared to indicate that most of the radioactivity was ether-soluble (table 7).

Amitrole, as such, does not appear to remain long in the fruit of the grape. Cation-exchangeable radioactivity was demonstrated only when the treated leaf was covered with a polyethylene bag; under these conditions, large quantities of activity migrated into the fruit.

Total radioactivity increased in the clusters with time. The most noteworthy increase was from the 2,4-D treatments of the leaves above the clusters in experiment 3 (table 7 ). The most nearly accurate readings were from the ether extract, since no correction for self absorption was required; furthermore, it was possible to planchet out considerable radioactivity. The radioactivity in the ethanol fraction and in the residue was diluted with a mass of sugars, et cetera, 112 days after treatment, so that it was not possible to planchet much radioactivity. The counts per minute above untreated check samples were low, so that the data for these fractions are only approximate-for both 2,4-D and amitrole.

An increase in total radioactivity in the clusters (tables 7 and 8 ) is associated with a decrease in the intensity of the autoradiographs (leaves, buds, tendrils, stems) between 23 and 112 days after treatment (figs. 13 to 16$)$.

\section{Activity in Flower and Fruit Clusters-Chromatography}

The ethanol extracts of the flower clusters that had radioactivity in them from experiment 2 (table 7 ) were evaporated nearly to dryness. The materials that were readily soluble in 50 per cent ethanol were dissolved by addition of a few drops of that material. In this way, large quantities of other materials present, which would have interfered with the chromatography, were not carried along with the extract. Some of the ethanol was then placed on filter paper for ascending chromatography. The solvent system used was 79 per cent isopropanol, 20 per cent of an aqueous solution of ammonium acetate (20 per cent), and 1 per cent glacial acetic acid. Some labeled 2,4-D also was spotted on the paper. After chromatogramming, the paper was dried and exposed to X-ray film for 30 days. The only radioactive spots present had an rf of 0.61 to 0.65 , which was identical with spots made by the labeled 2,4-D. The activity making these spots was from clusters that were collected three and 21 days after the lower leaves had been treated with labeled 2,4-D.

Chromatograms were made of the ether extracts shown in table 7 . The only detectable spots from extracts of clusters sampled three and 23 days after treatment had an rf of 0.61 to 0.65 , the same as for 2,4-D noted above. The extracts of fruit 112 days after treatment gave four spots on the chromatogram, with about 85 per cent of the activity having an rf the same as 2,4-D. The other three spots had rfs of $0.18,0.28$, and 0.86 , respectively. Some of the extracts from these grapes were applied to cotton seedlings, fol- 
lowing the bioassay method described by Leonard, Weaver, and Kay (in press). Strap-shaped cotton leaves, typical of 2,4-D injury, were produced in some cases.

The only spot that was developed on X-ray film of chromatograms of the ethanol- and cation-exchangeable eluates was that noted in table 8 . The material chromatographed as a single spot with an rf of 0.52 to 0.55 , the same as labeled amitrole. The leaf had been covered with a polyethylene bag in order to produce a saturated atmosphere; under these conditions, the absorption of amitrole was considerable.

\section{Distribution of Radioactivity in Stem Cross-sections, Leaves, and Clusters}

Some radioactivity in stem cross-sections occurred in the vicinity of the cambium within three days after treatment (figs. 17 and 20). The greatest accu-
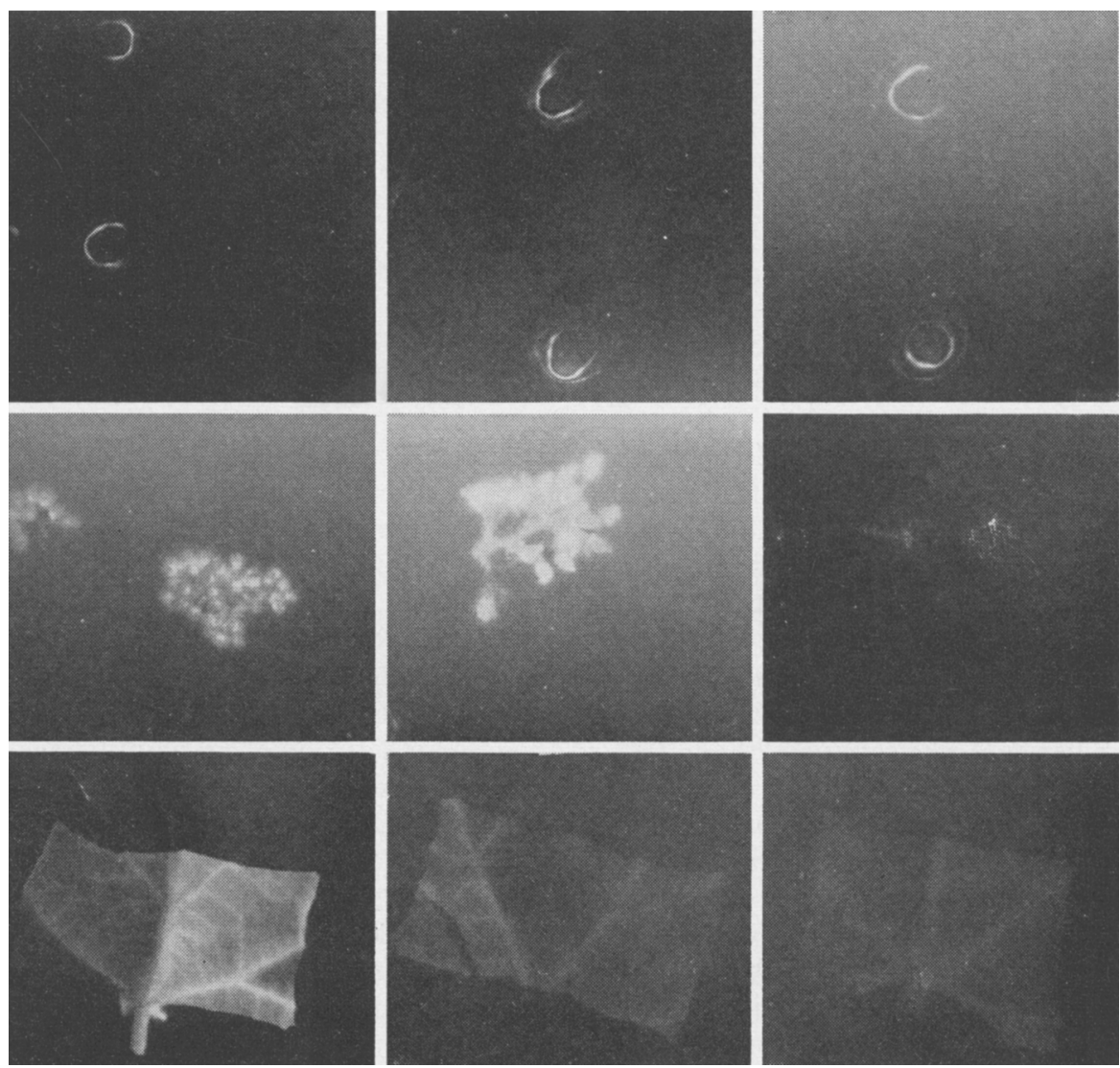

Fig. 20. Effect of treating first leaf below cluster on the radioactivity in stem crosssections, cluster, and leaves, three, 23, and 112 days after treatment with amitrole on May 9 , 1960. Samples were obtained from the same positions and after the same treatment periods as the ones shown in figure 17 . 
mulation of 2,4-D appeared to be in the phloem, while amitrole was in the xylem next to the cambium; however, the accumulation of 2,4-D was greater than amitrole (figs. 17 and 20).

When the stems were examined 23 days after treatment, activity in the stem cross-sections from the 2,4-D treatments was reduced, with most of it gone from the phloem and much reduced in the xylem. Activity from amitrole treatments was now entirely gone, except for a narrow ring of intensely labeled xylem which persisted for 112 days (fig. 20). Because of secondary growth, this labeled zone was deeply buried in the xylem. Only traces of activity from the 2,4-D treatments persisted in the stems for 112 days.

When 2,4-D and amitrole were applied in midsummer (July 26), translocation occurred without producing a detectable autoradiograph in the stem cross-sections.

No radioactivity was present in leaves with an area more than 25 per cent that of the mature leaf at time of treatment. In the smaller leaves, 2,4-D became concentrated in the outer part of the major veins; the activity in the middle of the veins (xylem) and between the veins was much less. The radioactivity in these same leaves became very greatly reduced by 112 days after treatment; the xylem appeared to be free of activity (fig. 17). Amitrole was more concentrated in the veins than between them (fig. 20), but the difference in concentration was less than with 2,4-D. There was activity in the central portion of the veins (xylem). The activity in the leaves 112 days after treatment had decreased less than for comparable treatments with 2,4-D.

The treatments in experiments 1,2 , and 3 were applied when the flowers were in the prebloom stage. Within three days after treatment, the activity in the clusters from the 2,4-D treatments was concentrated in the stems, pedicels, and receptacles (fig. 17). With amitrole, the stems were much less intensely labeled (fig. 20), while the flower was more strongly labeled than with 2,4-D.

Twenty-three days after treatment, flowering had occurred and the calyptras had fallen. 2,4-D was most concentrated in the pedicels. It was concentrated in the anthers in some cases, although most stamens were dried up at the second sampling. A pronounced black autograph was produced by the stigma of the young fruit. A few dark spots occurred at the vein tips of the young leaves.

The distribution of amitrole in the flowers 23 days after treatment was quite different from that of 2,4-D. The activity was concentrated in the small fruit that would subsequently shatter or absciss. Also, there was little activity in the stems or pedicels.

Activity in the fruit 112 days after treatment with 2,4-D was greatest in the pedicels, seed, and skin. Amitrole had a somewhat similar distribution, but was much less concentrated than 2,4-D, and probably more diffusely distributed.

When the 2,4-D and amitrole were applied in midsummer (July 26), there was no visible accumulation in the seed. The 2,4-D treatments resulted in some activity in the skins of the fruit; the amitrole treatments resulted in the fleshy portions of the fruit being more uniformly labeled (fig. 19). 


\section{DISCUSSION}

\section{Absorption of 2,4-D and Amitrole}

Amitrole and 2,4-D are both readily absorbed by the leaves of the Tokay grape, as shown by radioactivity in the treated leaves and in the shoots. However, direct measurements of absorption were not made. It is considered that some loss of radioactivity from the treated leaves was due to causes other than absorption, including decomposition and $\mathrm{CO}_{2}$ evolution, and physical loss of activity from the treated leaves by flaking off of cuticle.

It was not possible to increase the quantity of 2,4-D migrating into the grape clusters by bagging the treated leaf with a polyethylene bag. This result suggests that absorption of 2,4-D was not improved by a saturated atmosphere under the conditions of this one experiment.

The absorption of 2,4-D appeared to continue for a period of perhaps three weeks; furthermore, the results suggest that an appreciable percentage of the applied 2,4-D could be absorbed. Amitrole, on the other hand, appeared to be absorbed over a period of not much more than three days; however, the percentage of unabsorbed amitrole is unknown. The activity of gorse and broom leaves did not change much beyond three days after treatment, even though the amount of amitrole that could be washed from the leaves diminished markedly with time (unpublished work by the authors). The results suggest that amitrole became incorporated into water-insoluble complexes or other compounds.

\section{Translocation as Influenced by Leaf Size}

At Davis, California, shoots of the grape start growth around April 1. The rate of growth is rapid until about the middle of June, and is usually slow thereafter. The shoot tip consists of six to eight developing leaves, the ones basal to these being mature or full size.

The grape leaves appeared to reach the compensation point and become exporting when they had attained about one-half the width that they would have at maturity (about 25 per cent of the area). The precise time and nature of the transition from an importing to an exporting leaf need further study. Young leaves failed to export either 2,4-D or amitrole until the translocation pattern within them had become reversed; this required more than one day and sometimes more than three days. The effect of 2,4-D on a leaf was to inhibit or restrict its growth, but this did not keep it from becoming an exporting leaf. In other words, these leaves became physiologically more mature, even though maturity was not expressed in leaf size.

It appears that once a leaf has become exporting, polarity of movement within it is such as to prevent its becoming an importing leaf again (Leonard, 1939 ; Barrier and Loomis, 1957 ; Loomis, 1945). Barrier and Loomis (1957) found that $\mathrm{P}^{32}$ was translocated in a polar manner from the mesophyll to the veins of detached leaves; this polar movement (loading) even occurred in complete darkness, although to a lesser extent than in light.

When very young leaves were treated with 2,4-D (as with the upper leaves in experiments 1 and 2), the leaves themselves were markedly injured. This injury resulted in the death of some of the blade tissue and caused some 
2,4-D to migrate out of these leaves and upward to the tips of the stems. This movement was not thought to result from normal translocation, but from killing of some of the blade tissue, thus allowing some 2,4-D to move into the xylem, from which it could go anywhere the water went. The total of such movement out of these very small treated leaves was always quite small.

\section{Translocation of 2,4-D and Amitrole}

When the shoots were growing vigorously, translocation was strictly apical (experiments 1 and 2). The stage of development of the cluster may have a great deal to do with the direction of movement. Activity of the young cluster at prebloom stage, when it was about 4 inches long, was not sufficiently powerful to induce a reversal of translocation either from leaves treated directly above it (experiment 1 ) or from the second leaf above it (experiment 2 ). In other words, the shoot apex was a far more powerful sink than was the cluster in these experiments. Reversal of movement from the second treated leaf above the cluster did occur in experiment 3 , but not until after more than three days had elapsed following treatment. The downward movement resulted in a migration of both 2,4-D and amitrole to the clusters and to the stems below the clusters.

Translocation appears to be from "source to sink" (Zimmermann, 1960). Early in the season, when shoots are rapidly growing, a great number of sinks have to compete in some manner for food materials. Exogenous materials, such as 2,4-D and amitrole, appear to flow along with such food materials (Crafts, 1956; Crafts and Yamaguchi, 1958; Zimmermann, 1960). (The physiology of the phloem has been reviewed by Esau, Currier and Cheadle, 1957.) The sinks include the cambium, flower or fruit clusters, axillary buds that are developing, the shoot apex, immature leaves (one-half or less the width of mature leaves), and tendrils. The roots are sinks, but they do not obtain any food from the young, developing shoots; however, some movement down the stems occurs after the young shoots have reached a length of 3 or 4 feet, but this seems to vary. For example, there was no downward translocation of 2,4-D from the leaves above the clusters in experiments 1 and 2, even 21 days after treatment, when the shoots had attained a length of 4 feet; but downward translocation from similar leaves had occurred in experiment 3 by the time the shoots had attained that length. Downward translocation from the leaves below the cluster will occur before such movement takes place from leaves above the clusters. Some downward movement from such leaves had occurred within three days after treatment in experiment 3 , but none was observed from any of the treatments in experiments 1 and 2. The relationship of leaf maturity and position on the grape shoot to direction of translocation are similar to results obtained by Charles R. Hale (personal communication, 1961). He traced the translocation of the products of photosynthesis following exposure of the leaves to labeled carbon dioxide. Simultaneous two-directional movement from a treated leaf was common, although unidirectional movement occurred, depending on the location of the sinks.

Translocation appears to be more longitudinal than lateral. It takes place largely on the side of the stem of the treated leaf. The buds and young leaves 
on that side usually become more intensely labeled than do similar buds and leaves on the opposite side. As the distance above the point of application is increased, labeling in the stem becomes less localized, until the entire stem becomes labeled. Anastomosis of the primary phloem at the nodes might possibly explain the eventual uniform lateral distribution of the labeling. Downward movement in the stems of the grape and other woody plants appears to result in a restriction in the percentage of the phloem conducting the label (Leonard and Crafts, 1956) ; this conduction would be in secondary phloem, and anastomosis would not be involved. Zimmermann (1960) discusses the limited lateral movement of materials in the phloem. Grape flower clusters are sinks. In the prebloom stage, however, translocation was not deflected to the cluster from a leaf located on the opposite side of the stem and below the cluster (fig. 12).

2,4-D appears to increase the activity of sinks that are already present, and may also induce the development of secondary sinks (Leonard, 1958). Such sinks tend to restrict the translocation of 2,4-D. Existence of secondary sinks was only temporary in the shoots, since most of the radioactivity had disappeared from the leaves and the stems by 112 days following treatment (fig. 17). The temporary existence of these sinks may have been due to the detoxification of the 2,4-D. When the 2,4-D was applied in midsummer, no accumulation of activity was evident in the stems (fig. 18). Evidently the stems were not sinks at that time of year, at least for the small quantity of 2,4-D employed. Translocation definitely did occur through these stems, since there was appreciable radioactivity in the fruit resulting from treatment of either the leaf below the fruit cluster or the second leaf above the fruit cluster, with either 2,4-D or amitrole. Furthermore, free 2,4-D was recoverable from the fruit. However, the total amount of radioactivity reaching the fruit from the summer treatments was far less than from similar treatments made in the spring during the flowering period. By midsummer the vines and trunks had probably become strong sinks, followed in September-October by the roots (Winkler and Williams, 1945).

It is suggested that materials flowing from source to sink may migrate, following one or more different channels of sieve tubes. There is no apparent reason why translocation in adjacent sieve tubes must necessarily be in the same direction. It is possible that the sinks supplied by various sieve tubes may shift rapidly, depending upon the metabolic activity of the sinks (Zimmermann, 1960). Such a shift probably occurs in the mesophyll of voung leaves, when polarity becomes established and the leaves become exporting rather than importing. The bidirectional translocation of $\mathrm{C}^{14}$ and $\mathrm{P}^{32} \mathrm{de}-$ scribed by Biddulph and Cory (1960) may be on the basis of source and sinks as presented above.

\section{Storage and Fate of 2,4-D and Amitrole}

2,4-D is relatively stable within the clusters since about one-third of the total activity in the fruit was still present, as 2,4-D, 112 days after treatment. The fruit was nearly ripe at that time (15 per cent total soluble solids). The ethyl ether-soluble extracts of the fruit consisted of about 85 per cent 2,4-D as determined chromatographically; the remaining 15 per cent was distributed among three unidentified spots on the chromatograms. The composition 
of the ethanol-insoluble portion is unknown. The ethanol-soluble extracts of the flower clusters 23 days after treatment contained most of the radioactivity, present mainly as free 2,4-D in the ethanol extract.

It is generally believed that auxins applied to foliage remain active in the plant for only a limited time (Leopold, 1955). The grape is evidently an exception.

2,4-D was concentrated in the flower pedicels, as determined by autoradiography. It was present in high concentration at the apices of the young ovaries or berries. The stigma and anthers appeared to be strong sinks. At harvest time, 2,4-D (and label originating from 2,4-D) was present in the pedicels of the fruit, the stems of the clusters, the seed, and the skin of the fruit. However, the radioactivity in these plant parts was considerably lower than it was soon after flowering (fig. 17). When the applications were made in midsummer, 2,4-D became concentrated in and near the skin of the fruit.

Amitrole contrasted strikingly with 2,4-D with respect to its recovery from the flowers or fruit. No amitrole was recoverable as such, except from the midsummer treatment when the treated leaf was covered with a polyethylene bag to produce a saturated atmosphere. Under these conditions, amitrole was absorbed in large amounts, and migrated to the fruit. About 25 per cent of the activity in the fruit was cation-exchangeable three days after treatment; this same material appeared to chromatograph as amitrole when released from the resin.

Amitrole was present in a narrow, radioactive band in the xylem soon after the treatments were applied, and this band persisted for 112 days after treatment. Amitrole was mainly evident in the small ovaries or berries, probably because the larger ones diluted the activity within them as they developed. Activity appeared to be primarily present in the seed and the skin at harvest, but the autoradiographs shown were not strong enough to be reproduced (fig. 20). When the applications were made in midsummer, the amitrole appeared to be uniformly distributed in the fleshy portions of the fruit, but no radioactivity appeared to be present in the seed (fig. 19).

\section{Practical Aspects}

Some 2,4-D will migrate into the fruit from applications to the mature leaves during the growing season; shoot tip applications made before flowering may or may not show a similar result. Careful application with a shielded boom, such as described by Yates (1960), will help reduce the quantity of 2,4-D reaching the leaves. Less 2,4-D appears to go into the fruit from midsummer application in California than from similar applications made during the flowering period.

\section{SUMMARY}

Carbon-14 labeled 2,4-D and amitrole were applied to the leaves of the Tokay grape in four different experiments. Applications were made to the leaf directly beneath the cluster and to the first or second leaf apical to the clusters. A small leaf near the shoot apex was treated in two experiments. In three experiments, rapidly growing shoots were treated in the spring, and in the fourth experiment shoots were treated on July 26 after most active shoot growth had ceased. Portions of the leaves, buds, stems, clusters, and 
tendrils were collected for autoradiography at different periods following the applications. Flower and fruit clusters were saved for study of the labeled materials within them. The treated leaves were saved in order to determine the radioactivity remaining after different periods of time.

Both 2,4-D and amitrole were readily absorbed by the grape leaves. The absorption period for amitrole appeared to be no more than three days, while 2,4-D may have been absorbed for three weeks or more. The efficiency of absorption of 2,4-D by the grape leaf appeared to be considerable. However, in addition to translocation, other factors influenced the loss of radioactivity from the treated leaves.

During translocation, both 2,4-D and amitrole moved from source to sink. The sinks included the cambium, growing axillary and apical buds, tendrils, clusters, and immature leaves (one-half the width or less of mature leaves). Radioactivity in the flower clusters, from 2,4-D treatment, went into the anthers, pedicels, and young ovaries or berries. The activity of amitrole appeared to be greatest in the smallest berries-probably the ones that did not grow and would subsequently absciss as "shot berries." The larger berries had presumably diluted the radioactivity within them, because not much translocation of amitrole occurred beyond three days following treatment.

When the applications were made to leaves after the berries were about half-grown, 2,4-D concentrated in and near the skin, but radioactivity from amitrole was more generally distributed, except that very little collected in the seeds. 2,4-D was recoverable from the fruit 38 days after treatment, but the quantity present was less than one-third that from comparable treatments made during the flowering period. Amitrole, as such, was not recoverable except when the treated leaf was covered with a polyethylene bag to induce a saturated atmosphere. In that experiment, about one-third of the activity in the fruit was amitrole three days after application.

Translocation was only apical when the flowers were in the prebloom stage. The upward translocation occurred from fully enlarged leaves below the cluster and immature leaves above the clusters. Translocation became partially reversed during the course of the third experiment, continuing toward the shoot apex, but also basipetally into the clusters and the stem below the clusters.

Some activity persisted in the stem from the amitrole treatment, and traces with 2,4-D treatments. The label from amitrole was present in a narrow ring of xylem about two-thirds in toward the pith from the cambium.

Leaves one-half or less the width of mature leaves imported radioactivity from both 2,4-D and amitrole treatments. The blades were more uniformly labeled with amitrole than with 2,4-D. Labeling of these leaves was greatest three days after treatment with amitrole and 23 days after treatment with 2,4-D. The limited period of translocation of amitrole and the much longer period of translocation of 2,4-D in the grape shoot are believed to account for these differences. As the leaves enlarged and became exporting, the entire vein appeared to remain labeled from the amitrole treatments, but only the outer portions of the veins (not the xylem) were labeled with the $2,4-\mathrm{D}$. The total radioactivity in the leaves from both chemicals had very greatly faded by 112 days after treatment.

2,4-D was probably present in the free form in the Tokay grape shoots for 
at least three weeks. It was moderately stable in the clusters since one-third their total radioactivity 112 days after treatment was still recoverable as free 2,4-D.

Amitrole appears to remain for a short time within the shoots or the fruit of the Tokay grape before it is either complexed or broken down. Amitrole was not recoverable, as such, from the clusters, except within three days after treatment.

\section{ACKNOWLEDGMENTS}

The authors wish to express their thanks to Dr. Shogo Yamaguchi and Mr. A. L. Johnston for assistance in conducting these tests. Labeled amitrole was supplied by Amchem Products, Incorporated, and 2,4-D and certain facilities through A.E.C. Contract AT(11-1)-34, Project No. 9.

\section{LITERATURE CITED}

BARRIER, GEORGE E., and W. E. LOOMIS

1957. Absorption and translocation of 2,4-dichlorophenoxyacetic acid and $\mathrm{P}^{32}$ by leaves. Plant Physiol. $32: 225-31$.

BIDDUlPH, O., and R. CoRY

1960. Demonstration of two translocation mechanisms in studies of bidirectional movement. Plant Physiol. 35:689-95.

Clor, MaHMOOD ABBAS

1959. Comparative studies on translocation of $\mathrm{C}^{14}$-labeled 2,4-D, urea, and aminotriazole in cotton and oaks. Ph.D. thesis, University of California, Daris. 1-139.

Crore, W. J., and V. F. Bruns

1953. The sensitivity of the Concord grape to 2,4-D. Proc. Amer. Soc. Hort. Sci. $61: 125-34$.

Crafts, Alden S.

1956. Translocation of herbicides. I. The mechanism of translocation: methods of study with $\mathrm{C}^{14}$-labeled 2,4-D. Hilgardia 26(6):287-334.

1959. Further studies on comparative mobility of labeled herbicides. Plant Physiol. $34: 613-20$.

Crafts, A. S., and S. Yamaguchi

1958. Comparative tests on the uptake and distribution of labeled herbicides by $Z e$ brina pendula and Tradescantia fuminensis. Hilgardia $27(16): 421-54$.

CurRier, H. B., and C. D. Dybing

1959. Foliar penetration of herbicides-review and present status. Weeds 7:195-213.

Esau, K., H. B. Clrrier, and V. I. Cheadle

1957. Physiology of phloem. Ann. Rev. Plant. Phys. 8:349-74

LEONARD, O. A.

1939. Translocation of carbohydrates in the sugar beet. Plant Physiol. 14:5j- 74 .

1958. Studies on the absorption and translocation of 2,4-D in bean plants. Hilgardia $28(5): 115-60$.

1961. The absorption and translocation of acid and ester forms of labeled 2,4,5-T in gorse and broom seedlings. Western Weed Control Conference, Research Progress Rept.

Leonard, Oliver A., and Alden S. Crafts

1956. Translocation of herbicides. III. Uptake and distribution of radioactive 2,4-D by brush species. Hilgardia $26(6): 366-415$.

Leonard, O. A, and L. A. Lider

1961. Toxicity and translocation of herbicides supplied to grape rootings through solution culture. Amer. Jour. Enol. and Vit. 12:37-46.

LeONARD, O. A., R. J. WeAver, and B. L. KAY

Bioassay method for determining 2,4-D. Weeds (in press). 
LeOnard, O. A., and J. S. Yeates

1959. The absorption and translocation of radioactive herbicides in gorse, broom, and rushes. New Zealand Weed Control Conference 12:93-98.

LEOPOLD, A. C.

1955. Auxins and plant growth. Berkeley: University of California Press.

Lider, L. A., O. A. LeONARD, and R. L. Sisson

1961. Effect of amitrole upon poison oak and grape vines in a vineyard. Western Weed Control Conference Research Progress Rept.

Loomis, W. E.

1945. Translocation of carbohydrates in maize. Science 101:398-400.

SANDERS, H. G.

1958. Weed control handbook. The British Weed Control Council. Oxford: Blackwell Scientific Publications, pp. 200-01.

Weaver, R. J., O. A. LeOnard, and S. B. McCune

1961. Response of clusters of Vitis vinifera grapes to 2,4-dichlorophenoxyacetic acid and related compounds. Hilgardia 31(5):113-25.

Weaver, R. J., A. J. Winkler, and S. B. McCune

1958. Some effects of 2,4-dichlorophenoxyacetic acid and related compounds on the grapevine. Amer. Jour. Enol. and Vit. $9(3): 126-38$.

WINKLER, A. J.

1932. The lateral movement of elaborated foods in the grape vine. Amer. Soc. Hort. Sci. Proc. $29: 335-38$.

Winkler, A. J., and W. D. Williams

1945. Starch and sugars of Vitis vinifera. Plant Physiol. 20:412-32.

WINKLER, W. O.

1959. Methods for determination of amino triazole in fresh cranberries. Washington, D.C.: Div. of Food, Bur. of Biol. and Physiol. Sciences, Food and Drug Mimeo.

Yamaguchi, S., and A. S. Crafts

1958. Autoradiographic method for studying absorption and translocation of herbicides using $\mathrm{C}^{14}$-labeled compounds. Hilgardia $28(6): 161-91$.

Yates, Wesley E.

1960. Minimizing spray drift hazards. Down to Earth $16(2): 15-20$.

ZimMERMANN, MaRTiN H.

1960. Transport in the Phloem. Ann. Rev. Plant Physiol. 11:167-90. 
The journal Hilgardia is published at irregular intervals, in volumes of about 600 pages. The number of issues per volume varies.

Subscriptions are not sold. The periodical is sent as published only to libraries, or to institutions in foreign countries having publications to offer in exchange.

You may obtain a single copy of any issue free, as long as the supply lasts; please request by volume and issue number from:

\author{
Agricultural Publications \\ 207 University Hall \\ 2200 University Avenue \\ Berkeley 4, California
}

The limit to nonresidents of California is 10 separate issues on a single order. A list of the issues still available will be sent on request.

In our publications it is sometimes convenient to use trade names of products or equipment rather than scientific identifications. In so doing it is unavoidable in some cases that similar products which are on the market under other trade names may not be cited. No endorsement of named products is intended nor is criticism implied of similar products which are not mentioned. 
$4 x^{2} x$

$y^{2}+(x)+1$ $\frac{x}{4} x$

(1) दो

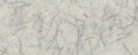

